\title{
Aplicación de la teoría del valor extremo y cópulas multivariadas para la medición del VaR de un portafolio de monedas de países latinoamericanos
}

Beatriz Manosalva-Galvis*

* Magíster en Finanzas. Donor Relations Manager, Latin America Region. The Nature Conservancy (TNC) [bmanosalvagalvis@gmail.com], [ORCID: 0000-0003-1982-1629].

Artículo recibido el 01 de marzo de 2020.

Aceptado el 01 de abril de 2020.

Para citar este artículo:

Manosalva-Galvis, B . (2020). Aplicación de la teoría del valor extremo y cópulas multivariadas para la medición del VaR de un portafolio de monedas de países latinoamericanos. ODEON, 18, 99-159.

DOI: https://doi.org/10.18601/17941113.n18.04 


\section{Resumen}

Se aplica la teoría del valor extremo (EVT, por sus siglas en inglés), junto al enfoque de cópulas para la estimación del valor en riesgo (VaR) y el Expected Shortfall (ES) de un portafolio de cinco monedas de países latinoamericanos en base dólar (COP, PEN, BRL, MXN y CLP). Se evalúa un portafolio óptimo sin apalancamiento, uno óptimo apalancado y un portafolio con iguales ponderaciones para todas las divisas, y se comparan con medidas de riesgo tradicionales, incluido el ajuste de las colas pesadas de la distribución de los rendimientos de cada activo y la estimación de la relación de dependencia de estos mediante el ajuste de las cópulas Gaussiana, $t$ y Clayton. Los resultados sugieren que la cópula de Clayton es la que recurrentemente mejora las estimaciones de riesgo para los portafolios propuestos, y que el ES arroja mejor desempeño según las pruebas de cobertura condicional y no condicional del modelo y según el porcentaje de fallos de cada medición.

Palabras clave: portafolio; valor extremo; valor en riesgo; cópulas.

Clasificación JEL: C29, C40.

\section{Abstract}

The Extreme Value Theory (EVT) is applied together with the copula approach to estimate the Value At Risk (VaR) and the Expected Shortfall (ES) of a portfolio of five currencies of Latin American countries on a dollar basis ( COP, PEN, BRL, MXN and CLP). An optimal portfolio without leverage, an optimal leveraged portfolio and a portfolio with equal weights for all currencies are evaluated and compared with traditional risk measures, including adjusting the heavy tails of the distribution of the returns of each asset and the estimation of the dependency ratio of these by adjusting the Gaussian copulations, $t$ and Clayton. The results suggest that the Clayton copula is the one that recurrently improves the risk estimates for the proposed portfolios and that the ES shows better performance according to the conditional and non-conditional coverage tests of the model and according to the percentage of failures of each measurement.

Key words: Portfolio; extreme value; value at risk; copulas.

JEL classification: C29, C40. 


\section{Introducción}

El valor en riesgo (VaR) es la medida más comúnmente utilizada en las finanzas modernas para el cálculo de la máxima pérdida probable de un portafolio o un activo para un horizonte de tiempo determinado, medido bajo un nivel de confianza específico. Los tres métodos más difundidos para su cálculo en la literatura son: la simulación histórica, la simulación de Monte Carlo y los métodos paramétricos. La simulación histórica se basa en el comportamiento de la historia de los datos, asumiendo que los datos históricos de los rendimientos tienden a repetirse en el futuro. Los métodos de Monte Carlo permiten simular trayectorias para los diferentes factores de riesgo a través de la generación de escenarios probables y aleatorios, dada una distribución de probabilidad. Por último, los métodos paramétricos asumen normalidad multivariada para el caso del análisis de riesgo de una cartera de activos.

En análisis de riesgos es frecuente encontrar que los rendimientos de los activos financieros sigan distribuciones diferentes a la normal. En este tipo de series de datos es común observar altos niveles de curtosis, lo que evidencia la presencia de colas pesadas, es decir que los eventos extremos tienen una probabilidad de ocurrencia más alta. Para la modelación de estas colas pesadas, la teoría del valor extremo (EVT, por sus siglas en inglés) ha sido ampliamente estudiada, dado que esta herramienta se enfoca en la obtención del mejor estimado posible del área de la cola de la distribución (McNeil, 1999). La EVT es un recurso estadístico que estudia los eventos raros o extremos de una serie de datos, lo que permite su modelación en el análisis de riesgos y mejora potencialmente su estimación. Sin embargo, Embrechts (2000) menciona que si bien el EVT complementa al modelo de VaR, explicando los eventos extremos de una distribución, es un enfoque que no debe ser usado separadamente, dado que no resuelve otros problemas de las series financieras como el de la dependencia. En respuesta a esto, autores como Di Clemente y Romano (2005), Wang et al. (2010), entre otros, han combinado el uso de EVT con las funciones cópula para modelar tanto colas pesadas como la dependencia en el análisis de riesgos.

Desde su introducción por Sklar (1959), las cópulas han constituido un enfoque de gran flexibilidad, dado que permiten combinar en una sola distribución de probabilidad multivariada diversas funciones marginales univariadas, con el fin de obtener una medida más precisa de la relación de dependencia de los factores de riesgo. De esta forma, la cópula permite calcular el VaR de una cartera 
donde sus activos no se distribuyen normalmente, determinando la estructura de dependencia tanto a nivel conjunto como individual.

La presente investigación busca evaluar si las medidas de desempeño del VaR para un portafolio de monedas de cinco países latinoamericanos (Colombia, Brasil, Perú, México y Chile) mejoran respecto a las mediciones tradicionales de riesgo, cuando se modelan conjuntamente las colas pesadas de la distribución usando la EVT, y la dependencia de los factores de riesgo, usando una cópula multivariada. Los portafolios propuestos son: portafolio óptimo sin apalancamiento, óptimo apalancado y de iguales ponderaciones.

La literatura ofrece diversas aplicaciones tanto de EVT como de cópulas en la modelación de riesgos, sin embargo, la mayoría de los estudios realizados se han enfocado principalmente en portafolios de índices y acciones para mercados como el norteamericano, europeo, asiático y, en menor medida, latinoamericano. A la fecha no se ha encontrado un estudio de caso que evalúe aplicaciones de cópulas y EVT para el cálculo del VaR para un portafolio de monedas de países latinoamericanos, dando relevancia a esta investigación como una solución para llenar ese vacío en la literatura e identificar si para el caso en mención, mejoran las medidas de desempeño del VaR mediante el uso de cópulas y EVT.

La estructura de la presente investigación es la siguiente: en la sección 1 se hace una revisión de la literatura tanto para las medidas de estimación de riesgos como el VaR y el Expected shortfall (ES), como para la EVT y cópulas. En la sección 2 se realiza un recorrido por los fundamentos teóricos para la aplicación de EVT y cópulas en el análisis de riesgos. En la sección 3 se describen los datos empleados para este estudio de caso y se analizan estadísticamente las series de tiempo empleadas. En la sección 4 se aplican los enfoques de EVT y cópulas en la medición de riesgo del portafolio y se contrastan las medidas de desempeño obtenidas por metodologías tradicionales con las que se obtienen tras usar conjuntamente EVT y cópulas. En la sección 5 se presentan las conclusiones del estudio de caso.

\section{Revisión bibliográfica}

\subsection{EI VaR y sus limitaciones}

Desde su introducción en 1995 por JPMorgan, el VaR ha sido la medida estándar usada para la medición de riesgo de activos y portafolios a nivel mundial. El 
concepto fue introducido como una medida de riesgo que permitía conocer la máxima pérdida posible de un portafolio o un instrumento financiero, medido bajo una probabilidad específica en un determinado horizonte de tiempo (J.P. Morgan/Reuters, 1996).

Los modelos comúnmente usados por las entidades financieras para el cálculo del VaR se clasifican en tres tipos: modelo paramétrico, simulación histórica y simulación de Monte Carlo.

El modelo paramétrico, o de varianza-covarianza, asume una distribución normal de los retornos, lo cual es su gran falencia dado que los datos en su mayoría presentan leptocurtosis y colas pesadas. Ignorar esta condición puede repercutir en que el modelo construido subestime la cola de la distribución de pérdidas y, por ende, la estimación del riesgo calculado mediante el VaR o el ES (McNeil, Frey y Embrechts, 2005). La simulación histórica no asume una distribución específica, sino que esta viene dada por la distribución empírica de las ganancias y pérdidas históricas del portafolio. De acuerdo con Uribe y Ulloa (2012), el supuesto principal en el que se fundamenta esta metodología es que la historia es un buen indicador del comportamiento futuro de un activo, lo cual afecta de manera directa la robustez del modelo, especialmente cuando hay poca información disponible sobre los factores de riesgo.

Por último, la simulación de Monte Carlo es un enfoque donde se simula una distribución teórica paramétrica para el cálculo del riesgo, lo que permite el uso de series de tiempo tanto dinámicas como estáticas. Según McNeil et al. (2005) tras escoger la distribución teórica se procede a simular números aleatorios de acuerdo con la distribución elegida, con lo cual se estima el riesgo usando VaR o Es con un nivel de significancia determinado. El beneficio de usar este modelo radica en que los cálculos efectuados pueden tener una mayor precisión dado que permite realizar estimaciones con una muestra de datos superior a la disponible originalmente.

En 1996, el Comité de Basilea adoptó la utilización del VaR como medida de riesgo, así como para el cálculo del capital que los bancos deben mantener para controlar su exposición al riesgo. Tiempo después, Artzner, Delbaen, Eber y Heath (1998) estudiaron las condiciones que debía tener una medida de riesgo para ser considerada como coherente. Ellos encontraron que una medida de riesgo $\rho$ es coherente si cumple con los siguientes axiomas (Artzner et al., 1998; Melo y Becerra, 2005): 
Sea $\rho: V \rightarrow \mathbb{R}$ una medida de riesgo, donde $V$ es un espacio de variables aleatorias conformada por los factores de riesgo de la cartera $(\mathrm{X}, \mathrm{Y})$ :

i) Invariante ante traslaciones (condición libre de riesgo): para toda variable aleatoria $X \in V$, y toda constante $\alpha \in \mathbb{R}, \rho(X+\alpha)=\rho(X)-\alpha$

Significa que añadir la constante $\alpha$ (libre de riesgo) a la posición inicial riesgosa $\mathrm{X}$, reduce el riesgo en la cantidad $\alpha$.

ii) Monotonicidad: para todo $X, Y \in V$, con $X \leq Y$, entonces, $\rho(Y) \leq \rho(X)$

Significa que si un portafolio $\mathrm{X}$ tiene retornos más bajos (presentando pérdidas mayores al de $\mathrm{Y}$ ) el riesgo de $\mathrm{Y}$ será menor que el de $\mathrm{X}$.

iii) Homogeneidad positiva: para todo $\lambda \geq 0$, y $X \in V, \rho(\lambda X)=\lambda \rho(X)$

Significa que posiciones más grandes implican un mayor riesgo.

iv) Subaditividad: para todo $X_{1}, X_{2} \in V, \rho\left(X_{1}+X_{2}\right) \leq \rho\left(X_{1}\right)+\rho\left(X_{2}\right)$

La subaditividad está estrechamente relacionada con el principio de diversificación, por tanto, es clave para el manejo de riesgos. Cuando esta condición se cumple, la suma de los riesgos individuales de los activos de un portafolio sería igual al riesgo global de este. Sin embargo, el cumplimiento de este axioma depende de que los rendimientos sigan una distribución normal, por lo que, en ausencia de normalidad, el VaR no sería una medida coherente de riesgo.

Otra limitante que presenta el VaR es que mide solo un cuantil de la distribución de pérdidas y ganancias ignorando cualquier pérdida que sobrepase su nivel, lo cual se conoce como "riesgo de cola" (Yamai y Yoshiba, 2005). Esta falencia puede resultar en pérdidas mayores a las estimadas por el VaR cuando se presentan eventos extremos.

Para superar las limitaciones del VaR, Artzner et al. (1998) propusieron el uso de la peor expectativa condicional (WCE, por sus siglas en inglés) también conocida como el ES, la cual se define como la pérdida esperada, condicionada a que esta supere el VaR. Esta medida de riesgo es propuesta como coherente, sin embargo, Acerbi y Tasche (2002) sugieren un ajuste adicional a la definición del 
ES, de modo que cuando se presentan distribuciones discontinuas, la coherencia de la medida no se vea afectada.

McNeil y Frey (2000) identificaron que, ajustando la distribución generalizada de Pareto (GPD, por sus siglas en inglés) y siguiendo la EVT, se generaban mejores estimaciones del ES que cuando se usa el modelo gaussiano. Ellos catalogaron el ES como una medida alternativa de riesgo con un buen fundamento teórico para ser aplicada a la medición de riesgos, dado que permite superar las deficiencias teóricas del VaR. Una de las contribuciones interesantes de los autores es el desarrollo de un enfoque para el backtesting de sus estimaciones de riesgo por ES. El portafolio en el que se basó esta investigación estaba compuesto por el índice S\&P500, el índice DAX, la acción de BMW, la tasa de cambio dólar/libra esterlina y el precio del oro.

Por su parte, Yamai y Yoshiba (2002) efectuaron una comparación entre el VaR y el es en cuanto a: i) el error de estimación (usando simulación de Monte Carlo), ii) la optimización de portafolios y iii) el método para descomponer el VaR y el ES en factores de riesgo. Dicha investigación concluyó que el ES es una medida que se puede optimizar y descomponer fácilmente, mientras que el VaR exhibe el comportamiento contrario. Asimismo, encontraron que el ES, contrario a lo que ocurre con el VaR, requiere un tamaño de muestra mayor para reducir el error de estimación. Para llegar a estas conclusiones, los autores escogieron dos tipos de portafolios: uno de 3 acciones y sus respectivas opciones call sobre dichos activos subyacentes, y otro de 1000 créditos del mercado japonés con tasas de incumplimiento homogéneas.

\subsection{La teoría del valor extremo como solución al problema de colas pesadas}

El VaR y el ES constituyen dos opciones para la estimación de riesgos. Sin embargo, algunos de los problemas que pueden presentar los retornos y que afectan directamente la precisión de las estimaciones obtenidas no son solucionados por medio de estas metodologías. Un ejemplo de este tipo de hechos estilizados que han sido ampliamente estudiados en la literatura financiera es la presencia de colas pesadas.

McNeil et al. (2005) plantean que las series de retornos diarios tienen usualmente una curtosis más alta que aquella correspondiente a una distribución normal, por lo que su distribución es leptocúrtica. Para asegurar que un modelo provea estimaciones de riesgo que tengan en cuenta el comportamiento de los 
valores extremos de las distribuciones, diversos autores como McNeil y Frey (2000), Embrechts (2000), Di Clemente y Romano (2005), Melo y Becerra (2005), Wang, Chen, Jin y Zhou (2010), entre otros, recomiendan el uso de la EVT. El argumento de McNeil y Frey (2000) para recomendar el uso de este enfoque radica en que las pruebas de backtesting confirmaron que cuando se empleaba EVT sumado a un modelo GARCH (Generalized AutoRegressive Conditional Heteroscedasticity), con un estimador de pseudo-máxima verosimilitud para el cálculo de la volatilidad condicional, se obtenía mejor desempeño en el VaR y el ES que cuando se estimaban las medidas de riesgo usando solo modelación GARCH o solo EVT. Un hallazgo similar se evidencia en Melo y Becerra (2005), quienes sugieren que las metodologías con mejor desempeño son las que modelan la varianza condicional (RiskMetrics, AR-GARCH y AR-GARCH-EVT). En favor del anterior argumento, Embrechts (2000) concluye que si bien el EVT complementa al modelo de VaR, explicando los eventos extremos de una distribución, es un enfoque que no debe ser usado separadamente, pues no es suficiente y no resuelve otros problemas de las series financieras como el de la dependencia. En virtud de lo anterior, algunos autores como Di Clemente y Romano (2005) y Wang et al. (2010) han optado por combinar el uso de la EVT con las funciones cópula (las cuales serán explicadas en mayor profundidad más adelante) para modelar tanto las colas pesadas como la dependencia, obteniendo mejores estimaciones de VaR frente al modelo tradicional.

La EVT se enfoca en estimar la probabilidad de ocurrencia de los eventos que son más extremos que los observados en una serie de datos (Melo y Becerra, 2005). Uno de los supuestos más importantes de esta teoría es que asume que los retornos extremos son independientes e idénticamente distribuidos (iid). Dado que dicha condición no se cumple en los retornos de los activos financieros, y ante la posible presencia de clústeres de volatilidad, McNeil y Frey (2000) y Nystrom y Skoglund (2002) recomiendan aplicar esta teoría sobre los errores estandarizados, los cuales se estiman con la ayuda de modelos ARMA-GARCH (Autoregressive Conditional Heteroscedasticity-Generalized AutoRegressive Conditional Heteroscedasticity). La literatura mencionada corrobora que los residuales estandarizados modelados están más cercanos a ser iid que la serie original.

Según McNeil (1999), en términos generales se pueden identificar dos métodos para definir valores extremos: el modelo de máximo por bloques o el modelo de picos sobre un umbral (POT, por sus siglas en inglés). 
En el método de máximo por bloques se identifican los eventos extremos durante un horizonte de tiempo, el cual se obtiene dividiendo la muestra en bloques uniformes sucesivos de igual tamaño. A partir del valor máximo de cada bloque se obtiene una serie de valores extremos. Para este método se emplean las distribuciones generalizadas de valor extremo (GEV, por sus siglas en inglés). Según lo señalan Melo y Becerra (2005), este método tiene varias desventajas, como que excluye los eventos que no corresponden al máximo dentro de su propio bloque. Asimismo, con su uso se corre el riesgo de perder parte de la información, a medida que el tamaño de los bloques se incrementa.

Por otra parte, el método POT es considerado por McNeil (1999) como uno de los más útiles en términos prácticos por su manejo eficiente de los datos extremos. Este método consiste en modelar el comportamiento de valores extremos que exceden un umbral, los cuales se definen como excesos. Los excesos sobre los umbrales se modelan a través de la GPD, la cual depende de unos parámetros de forma $\xi$ y de escala $\beta$ que pueden ser estimados a través del método de máxima verosimilitud. De acuerdo con el teorema Pickands-Balkema-de Haan (Balkema y De Haan, 1974; Pickands, 1975) o teorema del límite, toda distribución tiene un umbral a partir del cual la distribución de sus excesos se aproxima lo más cercano posible a la GPD. Además, el parámetro de forma que caracteriza la GPD queda fijado según la distribución inicial GEV, ya que caracteriza la distribución de sus bloques máximos.

Así entonces, la GPD incluye tres casos posibles de caracterización de las colas o de los excesos sobre un nivel de umbral dado (Lee y Kim, 2017):

- Distribuciones cuyas colas decrecen exponencialmente, como por ejemplo, la normal, se traducen en un parámetro de forma de Pareto generalizado $\xi$ igual a cero.

- Distribuciones cuyas colas decrecen como una polinomial o colas pesadas, como por ejemplo la $t$-student o la de Pareto, se traducen en un parámetro de forma de Pareto generalizado $\xi$ mayor a cero.

- Distribuciones cuyas colas son finitas o ligeras, como por ejemplo la beta, se traducen en un parámetro de forma de Pareto generalizado $\xi$ menor a cero.

En el método РОт, la elección del umbral representa un problema complejo. Como lo mencionan Melo y Becerra (2005), si se escoge un umbral muy bajo, se incluiría un mayor número de observaciones en la serie de máximos, pero se puede caer en el riesgo de obtener estimadores sesgados porque el teorema de 
límite ya no aplicaría. Por el contrario, si el umbral escogido es muy alto, se obtendrían estimadores con una alta varianza dado el bajo número de excesos.

Diversos autores han incluido en sus aplicaciones con EVT diferentes soluciones para llegar a un balance entre precisión y varianza en cuanto a la estimación del umbral óptimo. Nystrom y Skoglund (2002) sugieren construir estimadores de los parámetros de forma y escala basados en los datos y en la selección de un valor entero que represente la cantidad de datos de cada cola; posteriormente, proponen analizar la estabilidad de los estimadores respecto a la selección de dicho entero. Tras hallar los estimadores de máxima verosilimitud y siguiendo el método de estimación de Hill, concluyen que es el primero el que tiene un mejor desempeño en la estimación de los cuantiles de la distribución de pérdidas y ganancias, y que además tiene la propiedad de ser casi invariable a la selección del valor del umbral.

Fernández (2008) evalúa las propiedades del error cuadrático medio asintótico del estimador de Hill para la estimación del umbral, usando un algoritmo donde se minimiza este estadístico con base en un modelo de regresión exponencial. Por su parte, Yamai y Yoshiba (2005) siguen un enfoque similar, y basados en Embrechts, Kluppelberg y Mikosch (1996), grafican las funciones de medias de los excesos, para luego estimar los índices de cola para diversos umbrales. Finalmente, y para validar si la selección del umbral fue acertada, utilizan un método de bootstrap de dos pasos el cual había sido propuesto por Danielsson et al. (2001), con el fin de encontrar el umbral óptimo que minimice el error cuadrático medio asintótico.

Más recientemente, Wang et al. (2010) toman los excesos como el percentil 10 de la muestra y luego emplean conjuntamente el gráfico de la función de excesos de la media junto al estimador de Hill para determinar gráficamente el umbral óptimo.

Si bien no hay una metodología estándar que permita definir un nivel óptimo para el umbral, las más empleadas para su correcta identificación son: el gráfico de la media de los excesos (MEF, por sus siglas en inglés) y el método de Hill. El MEF consiste en el análisis de la linealidad de la relación entre un nivel de umbral dado y el valor esperado de los excesos asociados a dicho umbral, siendo el promedio muestral de la serie de los excesos el estimador de dicho valor esperado. Mediante este análisis se identifican intervalos en el gráfico donde la media de los excesos muestre un comportamiento lineal con pendiente positiva, los cuales corresponderían a un umbral óptimo. 
El método de Hill es otra metodología para la selección del umbral, fundamentada en el cálculo del estimador de Hill. El umbral se identifica mediante la construcción de un gráfico que contrasta los valores que adquiere el estimador de Hill para distintos umbrales. Los valores óptimos son aquellos donde el valor del estimador de Hill es estable. Otra forma de hallar el umbral óptimo es mediante la minimización del error cuadrático medio del estimador de Hill. Según Melo y Becerra (2005), algunos de los problemas que presenta esta metodología están relacionados con el desconocimiento de las propiedades de los estimadores cuando las muestras son finitas y con la sensibilidad del método a la selección del umbral, la cual puede llegar a ser alta, lo que da lugar a altos sesgos en el estimador de Hill, aun cuando el error cuadrático tenga un valor mínimo.

\subsection{Las cópulas y su rol en la modelación de la dependencia de los factores de riesgo}

Otro de los problemas que puede presentarse en la medición de riesgos es el de la dependencia entre los retornos de los activos de un portafolio. Es común que en la modelación de riesgos se emplee la correlación de Pearson como la herramienta para medir la asociación lineal entre las variables aleatorias. Sin embargo, Embrechts, McNeil y Straumann (2002) identificaron que la correlación de Pearson era una medida insuficiente, dado que solo mide la asociación lineal entre los rendimientos de los activos, sin tener en cuenta que esta asociación es más fuerte en presencia de eventos extremos. Igualmente, es una medida que solo logra explicar la dependencia lineal cuando la función de distribución es elíptica o cuando se satisface el supuesto de normalidad, pero como se mencionó, esta es una condición que no aplica generalmente en los retornos de los activos financieros. En respuesta a esto, diversos autores como Embrechts et al. (2002); Melo y Becerra (2008); Palaro y Hotta (2006), entre otros, han encontrado en las cópulas una manera efectiva de representar la dependencia entre instrumentos financieros.

Las cópulas fueron introducidas por primera vez en 1959 por Sklar. El teorema de Sklar, el cual constituye el fundamento de la teoría de cópulas, muestra que es posible descomponer cada función de distribución multivariada en sus respectivas distribuciones marginales y mínimo una cópula. Lo anterior ratifica que las cópulas tienen el potencial de explicar la estructura de dependencia de un conjunto de variables aleatorias dadas, en nuestro caso de retornos financieros. 
Melo y Becerra (2008) definen las cópulas como una función que aproxima el comportamiento conjunto de la dependencia de variables aleatorias basado en el comportamiento que estas siguen individualmente. Entre las ventajas que presenta el uso del enfoque de cópulas, los autores señalan las siguientes:

1. La cópula contiene información más detallada de la dependencia entre variables cuando se compara con el valor obtenido mediante la correlación de Pearson. Esto se explica porque la cópula extrae la estructura de dependencia de la función de distribución multivariada.

2. La cópula incorpora todos los tipos de dependencia, ya sea: dependencia perfecta positiva (variables comonotónicas), dependencia perfecta negativa (variables contramonotónicas) o independencia (cópula de independencia).

3. La cópula es invariante ante transformaciones crecientes, lo que muestra que la estructura de dependencia es invariante ante traslaciones.

4. La cópula puede incorporar diversas funciones de distribución porque su estructura de dependencia es independiente de las distribuciones marginales. Esto es bastante útil porque mediante su uso no se requiere partir del supuesto de normalidad para el análisis de riesgos, lo cual hace más realista un análisis de este tipo.

La función cópula puede ser de diversos tipos y también se clasifica en familias, las más representativas son las elípticas y las arquimedianas. Dentro de la familia de cópulas elípticas se encuentran la cópula Gaussiana (la cual explica la dependencia para una distribución normal multivariada) y la cópula $t$-student (distribución $t$-multivariada). Por otra parte, dentro de la familia de cópulas arquimedianas encontramos a la cópula de Frank, Gumbel y Clayton.

Desde que Embrechts et al. (2002) señalaron las limitaciones de la correlación lineal para la medición de riesgos aplicando el concepto de cópulas para modelar la dependencia, muchos autores han empleado esta herramienta en la modelación de riesgos. Gran parte de estas aplicaciones de cópulas para modelar la dependencia se ha enfocado principalmente en activos del mercado de Estados Unidos. Palaro y Hotta (2006), por ejemplo, usaron este enfoque para estimar el VaR para un portafolio compuesto por los índices Nasdaq y S\&P500, concluyendo que el uso de la cópula de Joe-Clayton simétrica (SJC cópula) producía los mejores resultados al medir el VaR.

En línea con lo anterior, Kole, Koedijk y Verbeek (2007) efectuaron una aplicación de cópulas para el análisis de riesgos en el caso de un portafolio combinado 
de índices del mercado de acciones, bonos e inmobiliario de Estados Unidos. En su trabajo identificaron que la cópula Gaussiana subestima las probabilidades, mientras que la Gumbel las sobrestima, por lo que la cópula $t$-student se presenta como la de mejor ajuste. Asimismo, concluyen que los estudios que solo incluyen la cópula Gumbel y Gaussiana pueden ser muy limitados.

También se destacan usos del enfoque de cópulas para los mercados de Europa, como el efectuado por Patton (2006), quien introdujo la cópula de Joe-Clayton simétrica para un portafolio compuesto por posiciones en marco/dólar y yen/ dólar, y concluyen que dichas tasas de cambio tienen una correlación más alta cuando estas se deprecian contra el dólar. Este hallazgo es interesante, porque refuta la existencia de simetría en la estructura de dependencia de las tasas de cambio y porque es de las primeras investigaciones en considerar cópulas para distribuciones condicionales variables en el tiempo.

Respecto al mercado local se destaca la contribución de Melo y Becerra (2008), quienes realizaron una revisión teórica detallada de las medidas de dependencia existentes, y escogieron a la cópula como la medida más adecuada para capturar la dependencia en la modelación de riesgos. Su aplicación al cálculo del VaR sobre un portafolio compuesto por posiciones en el IGBC, la TRM y un TES a 10 años arrojó que de las cinco cópulas analizadas (Normal, $t$, Gumbel, Clayton y Frank), la $t$-student tiene los mejores resultados en 5 de 7 criterios de selección analizados. En línea con la investigación anterior, Quevedo (2005) también exploró la relación de dependencia entre el mercado de TES y el de dólar, usando las cópulas Frank, Bв2 y Normal, esta última fue la de peor ajuste.

Torres y Olarte (2009) efectuaron el cálculo del VaR empleando el enfoque de cópulas, esta vez para un portafolio de cuatro acciones de alta bursatilidad del mercado colombiano, creando subportafolios de pares de activos riesgosos. Al modelar la dependencia con las cópulas, Clayton, Frank y Gumbel dedujeron que la estimación de riesgos mejora cuando se emplean las últimas dos, esto comparando los resultados obtenidos con la metodología tradicional de VaR por simulación histórica.

En aplicaciones más recientes del mercado local, Triana, Torres, Alba y Pineda-Ríos (2018) usaron la función cópula con argumentos bayesianos, con el fin de estimar el VaR de un portafolio de acciones de Bancolombia y Ecopetrol, y encontraron que el mejor ajuste se da con el uso de una cópula $t$ bivariada. Por su parte, Ceballos (2015) encuentra que al aplicar modelos ARMA-GARCH y la cópula $t$ al cálculo del VaR de un portafolio invertido en COP/USD y EUR/COP se obtienen estimaciones de riesgo mayores que las de los métodos tradicionales. 
En otra investigación aplicada al mercado latinoamericano, Loaiza, Gómez y Melo (2015) implementaron una metodología de vine cópula para analizar el nivel de contagio entre los tipos de cambio de México, Colombia, Perú, Brasil, Argentina y Chile, midiendo el contagio en términos de coeficientes de dependencia de las colas. El resultado arrojó que las tasas de cambio de Brasil, Colombia, Chile y México evidenciaban los mayores coeficientes de dependencia.

\subsection{Aplicaciones conjuntas de cópulas y teoría del valor extremo para la medición del valor en riesgo}

Con el propósito de mejorar el desempeño en la estimación del VaR se han dado diversas aplicaciones conjuntas de cópulas y la EVT, en mercados financieros de países desarrollados y en algunos emergentes. Di Clemente y Romano (2005), por ejemplo, sugieren combinar el uso de las cópulas Gaussiana y $t$-student junto con EVT, para el cálculo del VaR de una cartera de veinte acciones del mercado italiano; estos autores encuentran que el VaR estimado bajo el modelo cópula-EVT mejora su desempeño a un nivel de confianza del 99 y del 99,9\%.

Fernández (2008) también acude a modelar las colas de la distribución con EVT y la dependencia a través del uso de cópulas. Partiendo de una cartera de cuatro índices de acciones del MSCI (Morgan Stanley Capital International Index, por sus siglas en inglés) usó las cópulas de Clayton, Gumbel, $t$-student y Normal en la estimación del VaR. Este estudio, que empleó cópulas bivariadas, concluyó que la $t$-student explica mejor las relaciones de dependencia presentes. También encontró que la prueba de dependencia de Poon no aportó resultados satisfactorios para la selección de la cópula óptima. Estos hallazgos están alineados con lo encontrado por Bob (2013), en su aplicación de EVT-Cópulas y GARCH a la medición de VaR de un portafolio de índices de acciones de Alemania, España, Italia y Francia. Recurriendo a las cópulas Gaussiana, $t$-student, Clayton, Gumbel y Frank también encontró que, en particular, el VaR obtenido mediante simulación de Monte Carlo usando la cópula $t$-student y el enfoque conjunto con EVT, superaba en su desempeño al modelo conjunto con otras cópulas y a los modelos tradicionales de simulación histórica y varianza-covarianza (paramétrico).

Hussain y Li (2018) hacen un estudio de la estructura de la dependencia entre el mercado accionario de China y los mercados de Estados Unidos, Canadá, Reino Unido, Alemania, Japón y Australia; encuentran que la dependencia entre China y los demás países en general es baja y que la mayor dependencia se evidencia entre China y los mercados europeos y asiáticos. La dependencia más fuerte 
fue la encontrada entre los mercados de China y Australia, lo cual no había sido documentado en investigaciones previas.

Para el mercado de commodities, se destaca el trabajo de Yu, Yang, Wei y Lei (2018), donde se confirmó que la modelación de colas con EVT y la de dependencia con vine cópulas contribuyen a mejorar la precisión de la estimación del VaR y el ES para los retornos del petróleo. Específicamente, se identifica a la cópula mixta r-vine (la cual puede seleccionar diferentes cópulas binarias en cada extremo) como la de mejor ajuste cuando se compara con la R-vine Gumbel y la R-vine Joe.

Concretamente para el mercado de tasas de cambio, Wang et al. (2010) modelaron el riesgo para un portafolio de monedas (USD, EUR, JPY y HKD) usando un modelo GARCH-EVT con cópulas Gaussiana, $t$-student y Clayton; esto con el fin de evaluar la elección óptima de las ponderaciones de su portafolio. La conclusión fue que la cópula $t$-student era la que mejor describía la dependencia entre los activos del portafolio y que las ponderaciones óptimas de este no cambiaban significativamente con variaciones en la metodología de la estimación de la cópula y el nivel de confianza.

En la revisión de literatura específica sobre aplicaciones de este tipo para portafolios de monedas extranjeras en países emergentes, se encontraron ciertas referencias a investigaciones de países emergentes asiáticos. Hsu, Huang y Chiou (2011) estudiaron la relación entre la tasa de cambio y el índice del mercado accionario para Indonesia, Corea, Malasia, Singapur, Taiwán y Tailandia, y concluyeron que un enfoque conjunto empleando la cópula de Clayton y la EVT ofrecía el mejor desempeño en las estimaciones del VaR, comparado con el método tradicional.

En India, Karmakar (2017) realizó un estudio donde se modeló la estructura de la dependencia usando siete tipos de cópulas y un enfoque GARCH-EVT para las distribuciones marginales, para el cálculo del VaR y el CVaR. A fin de demostrar su efectividad usaron los datos de cinco monedas extranjeras comparadas con la rupia (INR): USD/INR, SF/INR, JPY/INR, GBP/INR y el EURO/INR. El modelo incluyó siete tipos de cópulas bivariadas: Gaussiana, Frank, Clayton, Gumbel, BB1, BB2 y BB7; y mediante el uso de criterios de información como el Akaike (AIC) y el bayesiano (BIC) se llegó a la conclusión de que la cópula BB1 era la que proveía el mejor ajuste.

En Latinoamérica, los modelos que usan conjuntamente cópulas y EVT para la estimación de VaR han sido empleados principalmente para portafolios con combinaciones variadas de activos, predominando el uso de índices, acciones y, 
en menor medida, monedas. Por ejemplo, Hotta, Lucas y Palaro (2008) propusieron un modelo donde se ajustaron los datos por heteroscedasticidad (usando ARMA-GARCH), y se usaron cópulas y EVT para estimar el VaR de un portafolio compuesto por los índices IBOVESPA (Brasil) y MERVAL (Argentina). Al estimar la cópula con la distribución marginal de Pareto, los autores encontraron un buen ajuste especialmente de la cola izquierda de la distribución. Feo (2016) también efectuó un estudio similar, tomando como activos los índices bursátiles de Argentina, Brasil, Chile, México y Perú, y empleando un enfoque de EVT junto con una cópula r-vine para el cálculo del VaR. Como resultado se identificó una dependencia condicional positiva entre las volatilidades de los activos de riesgo, siendo la más marcada entre Brasil y México, así como una subestimación de las mediciones de riesgo a través de los métodos tradicionales, cuando se comparan con el VaR obtenido usando la cópula R-vine y EVT.

En Colombia se encontraron algunas aplicaciones de ambos enfoques. Por ejemplo, Salinas, Maldonado y Díaz (2010) aplicaron EVT y cópulas a una cartera compuesta por dos TES en pesos, el índice IGBC y la tasa representativa del mercado (TRM), concluyeron que el enfoque conjunto, privilegiando las cópulas de mayor ajuste (Gumbel y Kimeldorf-Sampson), genera estimadores del VaR más acertados de acuerdo con las pruebas de backtesting efectuadas.

Recientemente, Alba, Pineda-Ríos y Deaza (2019) plantearon una combinación del uso de EVT con el de modelos Vinecópula ${ }^{1}$ para un portafolio que incluía las acciones colombianas: Preferencial Bancolombia, Sura y Ecopetrol. Tras esta aplicación se encontró que los modelos de vinecópula capturan adecuadamente la dependencia entre los activos del portafolio.

A pesar de que la oferta en la literatura de las aplicaciones de estas metodologías a portafolios de activos es amplia, hasta el momento no existen documentos donde se apliquen conjuntamente los enfoques de cópulas y EVT para el cálculo de mediciones de riesgo de portafolios de monedas de países latinoamericanos, esta es una de las razones que motivó este estudio.

1 La vinecópula es un método gráfico que permite capturar de una forma más flexible la estructura de la dependencia del portafolio de activos, mediante el uso de una estructura de árbol que incorpora cópulas bivariadas. 


\section{Metodología}

En esta sección haremos un recorrido por los fundamentos teóricos en los que se basa el presente estudio de caso. En primer lugar, hablaremos sobre la modelación de las distribuciones marginales de los residuales usando modelos univariados ARMA-GARCH, lo cual es clave para pasar al segundo punto que será la aplicación de EVT. El ajuste de esta teoría consistió en la calibración de la GPD como aproximación para la distribución límite de las excedencias sobre el umbral de los residuales estimados a partir de los modelos univariados, también se explican las herramientas en las que se basó la calibración de dicho umbral. En el tercer punto se expone la aplicación de cópulas para la modelación de la dependencia entre los factores de riesgo, para finalmente, en el cuarto punto, introducir la metodología que se seguirá para el cálculo del VaR y del es del portafolio escogido.

\subsection{Modelos Univariados - ARMA-GARCH}

En esta sección procedimos a modelar las distribuciones marginales empleando los modelos ARMA-GARCH. Como se mencionó, EVT supone que los datos a los que se aplica este enfoque son originalmente independientes e idénticamente distribuidos (iid), propiedad que ha sido ampliamente estudiada para el caso de series financieras, llegando a que es muy probable su incumplimiento (Melo y Becerra, 2005). Lo anterior se justifica por la presencia de autocorrelación serial, atributo que es inherente a las series de tiempo, y la heteroscedasticidad que caracteriza el comportamiento de los precios de los activos financieros, cuyo principal síntoma es la existencia de agrupamientos de volatilidad o clústeres.

Para lidiar con esta clase de problemas, Bollerslev (1986) y Engle (1982) propusieron los modelos ARMA-GARCH como una alternativa para filtrar los datos y garantizar su independencia y distribución idéntica (Koliai, 2016); esta clase de modelos asume que la varianza no condicional es constante en el tiempo, mientras que la varianza condicional se asume variable. De estos modelos obtendremos los residuales (iid), estandarizados por sus volatilidades dinámicas condicionales, sobre los cuales se ajustará la GPD y, posteriormente, la cópula multivariada.

Se asume que los logretornos $r_{s, t}$ de los precios relativos del dólar respecto a la moneda $s$ de la canasta seleccionada en el momento $t$ siguen un proceso autorregresivo de media móvil, ARMA (p,q), así: 


$$
r_{s, t}=c_{s}+\varepsilon_{s, t}+\sum_{i=1}^{p} \varphi_{s, i} r_{s, t-i}+\sum_{j=1}^{q} \theta_{s, j} \varepsilon_{s, t-j}
$$

donde:

$\varphi_{s, i}:$ parámetro del modelo autorregresivo (AR) asociado al rezago $i$ de los logretornos de los precios de la moneda $s$, con $i=1, \ldots, q$.

$\theta_{s, j}$ : parámetro del modelo de media móvil (MA) asociado al rezago $j$ de los residuales del modelo, donde $j=1, \ldots, p$.

$c_{s}$ : constante del modelo del activo $s$.

$\varepsilon_{s, t}$ : errores o residuales, a los que corresponden unos residuales estandariza$\operatorname{dos} Z_{s, t}=\frac{\varepsilon_{s, t}}{\sigma_{s, t}}$ donde $\sigma_{s, t}$ es la volatilidad condicional de $\varepsilon_{s, t}$ y se asume que $Z_{s, t} \stackrel{i i d}{\rightarrow} N(0,1)$

Se asume, además, que dicha volatilidad condicional de los residuales del modelo anterior sigue un proceso GARCH (p,q), de la siguiente forma (Vose, 2008):

$$
\sigma_{s, t}^{2}=\omega_{s}+\sum_{i=1}^{q} a_{s, i} \varepsilon_{s, t-i}^{2}+\sum_{j=1}^{p} b_{s, j} \sigma_{s, t-j}^{2}
$$

donde:

$a_{s, i}$ : parámetro del modelo autorregresivo (ARCH) asociado al rezago $i$ de los residuales del modelo de media de la moneda $s$, con $i=1, \ldots, q$.

$b_{s, j}$ : parámetro del modelo generalizado (GARCH) asociado al rezago $j$ de la varianza condicional, donde $j=1, \ldots, p$.

$\omega_{s}$ : constante del modelo de volatilidad condicional para el activo $s$.

Donde $\omega_{s}>0, a_{s, i} \geq 0$ y $b_{s, i} \geq 0$ garantizan la no negatividad de la varianza condicional, mientras que la varianza no condicional está dada por:

$$
\sigma_{s}^{2}=\frac{\omega_{s}}{1-\sum_{i=1}^{q} a_{s, i}-\sum_{j=1}^{p} b_{s, j}}
$$


Lo que implica que para que esta se defina, necesariamente se tiene que cumplir que $\sum_{i=1}^{q} a_{s, i}-\sum_{j=1}^{p} b_{s, j}<1$

\subsection{Teoría del valor extremo y distribución generalizada de Pareto}

Si los residuales estandarizados $z_{s, t}$ son iid y el modelo ajustado por activo está correctamente especificado, se procede a aplicar EVT en una segunda etapa de la modelación de las distribuciones marginales, esto con el fin de ajustar correctamente las colas de la distribución de los retornos. De acuerdo con Melo y Becerra (2005), la EVT es una herramienta que ha ganado predominancia en los últimos años en la medición de riesgos, dado que ofrece resultados asintóticos sobre la dinámica de los valores extremos de una variable aleatoria, lo que brinda mayor precisión a herramientas de medición de riesgos como el VaR.

Para obtener los valores extremos existen dos alternativas, el método de máximo por bloques y el método de picos sobre el umbral (POT, por sus siglas en inglés). Nos enfocaremos en esta última metodología dado que, como mencionamos, McNeil (1999) y Melo y Becerra (2005) ya habían advertido las limitaciones del método de máximo por bloques respecto al uso de la información sobre valores extremos, por lo que el método POT fue el escogido para este estudio.

En el método РОт, cualquier residual estandarizado $z_{s, t}$ que exceda el umbral $u$ es identificado como un exceso de retorno. Coles (2001) define el método POT de la siguiente forma: sea $Z$ una variable aleatoria con una función de distribución marginal $F$, se identifican como valores extremos cualquier $Z$ que exceda el umbral superior $u$. La distribución de los excesos está dada por:

$$
F_{u}(z)=\operatorname{Pr}\{Z \leq u+z \mid Z>u\}, 0 \leq z \leq Z_{u}-u
$$

Donde $z=Z-u$ es el exceso sobre $u$ y $Z_{u}$ es el extremo superior de la variable aleatoria. Siguiendo el enfoque de Pickands (1975), la función descrita anteriormente puede aproximarse a través de una GPD, por lo que a los errores estándar se ajustarán dos distribuciones: la GPD en las colas inferior y superior, y la empírica para el dominio remanente, así: 


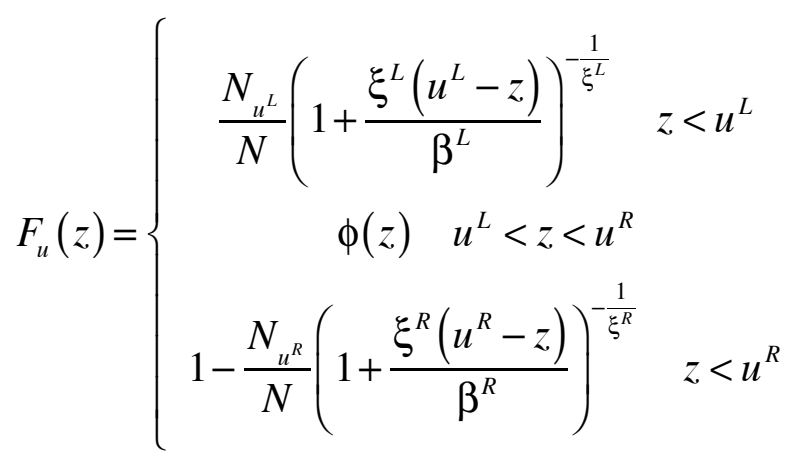

donde:

$\xi^{L}\left(\xi^{R}\right)$ : parámetro de forma de la GPD ajustada a la cola izquierda (derecha).

$\beta$ : parámetro de escala.

$u^{L}\left(u^{R}\right)$ : umbral inferior (superior).

$N_{u^{L}}\left(N_{u^{R}}\right)$ : número de excesos sobre el umbral inferior (superior).

$\mathrm{N}$ : número de observaciones incluidas en el ajuste de $F_{u}(z)$.

\subsubsection{Elección del umbral óptimo}

El primer método se basa en la esperanza de la GPD, de forma que si $z$ sigue la anterior definición $F_{u}(z)$, se tiene que para la cola superior:

$$
E(Z)=\frac{\beta^{R}}{1-\xi^{R}} \operatorname{con} \xi^{R}>1
$$

Si suponemos que la GPD es válida para modelar los excesos de un cierto umbral $u_{0}$, para un término arbitrario Y de la serie se tendrá:

$$
E\left(Y-u_{0} \mid Y>u_{0}\right)=\frac{\beta_{u_{0}}^{R}}{1-\xi^{R}} \operatorname{con} \xi^{R}>1
$$

Donde $\beta_{u_{0}}^{R}$ es el parámetro de escala de la distribución de excesos del umbral $u_{0}$. Entonces, si la calibración de la distribución de Pareto es válida para los excesos sobre $u_{0}$, también lo será para cualquier otro umbral superior mediante una sustitución del parámetro de escala por $\beta_{u}^{R}$. Entonces: 


$$
E(Y-u \mid Y>u) \frac{\beta_{u}^{R}}{1-\xi^{R}}=\frac{\beta_{u_{0}}^{R}+\xi^{R} u}{1-\xi^{R}}
$$

Se espera, entonces, que los valores de la anterior esperanza cambien linealmente ante variaciones en el umbral $u$ si sobre este nivel la calibración de la GPD es apropiada. El contraste ilustrativo entre el estimador de dicho valor esperado y los valores de los umbrales sobre los cuales se evalúa se denomina gráfico de vida media residual (MEF plot). Se tomará como candidato a umbral óptimo el valor alrededor del cual el gráfico muestra una tendencia lineal. Se sigue el mismo procedimiento para la cola inferior de la distribución.

El segundo método por seguir con el fin de determinar el umbral óptimo se basa en el estimador de Hill, que asume que para una variable aleatoria iid $Y_{1}, Y_{2}, \ldots, Y_{N}$, hay asociados unos estadísticos ordenados de forma descendente $Y_{(1, N)}>Y_{(2, N)}>\ldots>Y_{(N, N)}$. Asumiendo que la distribución de dichas variables aleatorias es de colas pesadas, el estimador de Hill, conocido como el estimador del parámetro de forma, se define como:

$$
H_{k, N}=\frac{1}{N} \sum_{i=1}^{k} \log \left(\frac{X_{(i, N)}}{X_{(k, N)}}\right), k \leq N
$$

Donde $k=N_{u}$ es el número de observaciones que son mayores al umbral. El gráfico de Hill se construye, entonces, a partir del estimador de Hill para el rango de los $k$ valores de la cola que sobrepasan el umbral contra el valor de este. El valor de $X_{(k, N)}$ a partir del cual el estimador de Hill tiende a ser estable puede ser seleccionado como candidato a ser el umbral óptimo.

Por último, se tomó como umbral óptimo aquel que cumple con ambos criterios expuestos anteriormente, esto se hizo mediante la intersección de los rangos en los que el gráfico de vida media residual muestra una tendencia lineal respecto al espectro de valores de umbrales, y en los que el estimador de Hill no presenta variaciones significativas. Para los casos en los que no se muestra una intersección concluyente, se procedió a calcular el valor medio de los extremos más cercanos de ambos rangos. 


\subsection{Cópulas}

Las cópulas son una función que permite combinar en una sola distribución de probabilidad multivariada diversas funciones marginales univariadas, de modo que se pueda obtener una medida más fiable de la relación de dependencia de los factores de riesgo. Una de las ventajas de este enfoque, el cual además prueba su flexibilidad, es que la cópula permite calcular el VaR de una cartera donde sus activos no siguen una distribución multivariada normal.

Como lo definen Melo y Becerra (2008), una cópula d-dimensional es una función de distribución multivariada $C:[0,1]^{d} \rightarrow[0,1]$ con distribuciones marginales individuales uniformes estándar $U_{i} \sim U(0,1) i=1,2, \ldots, d$ La cópula tiene las siguientes propiedades:

i) $C\left(u_{1}, \ldots, u_{d}\right)$, es creciente en cada componente $u_{i}$.

ii) $C\left(1, \ldots, 1, u_{i}, 1 \ldots, 1\right)=u_{i}$ para todo $i \in\{1,2, \ldots, d\}, u_{i} \in[0,1]$.

iii) Para todo $\left(a_{i}, \ldots, a_{d}\right),\left(b_{i}, \ldots, b_{d}\right)=\in[0,1]^{d}$ con $a_{i} \leq b_{i}$ se tiene que:

$$
\sum_{i_{1}=1}^{2} \ldots \sum_{i_{d}=1}^{2}(-1)^{i_{1}+\ldots+i_{d}} c\left(u 1_{i_{1}}, \ldots, u_{d i_{d}}\right) \geq 0
$$

donde $u_{j 1}=a_{j}$ y $u_{j 2}=b_{\mathrm{j}}$ para todo $j \in\{1,2, \ldots, d\}$.

iv) Para cada cópula $C\left(u_{1}, \ldots, u_{d}\right)$ se tienen los siguientes límites (los cuales se conocen como límites de Fréchet):

$$
\max \left\{\sum_{i=1}^{d} u_{i}+1-d, 0\right\} \leq C(u) \leq \min \left\{u_{1}, \ldots, u_{d}\right\}
$$

De las propiedades previamente mencionadas se puede afirmar que solo la $i$ ), iii) y $i v$ ) son características de todas las funciones de distribución multivariada, mientras que la $i$ ) menciona que las funciones de distribución marginales son uniformes estándar (McNeil et al., 2005; Melo y Becerra, 2008).

El teorema de Sklar (1959), en el cual se basan las funciones cópula, se define de la siguiente forma: sea $F\left(z_{1}, \ldots, z_{d}\right)$ una función de distribución conjunta de 
las variables aleatorias (residuales estandarizados) $Z_{1}, \ldots, Z_{d}$ con funciones de distribución marginales $F_{1}\left(z_{1}\right), \ldots, F_{d}\left(z_{d}\right)$ Existe una función cópula de variables aleatorias $C:[0,1]^{d} \rightarrow[0,1]$ tal que (Melo y Becerra, 2008):

$$
F\left(z_{1}, \ldots, z_{d}\right)=C\left(F_{1}\left(z_{1}\right), \ldots, F_{d}\left(z_{d}\right)\right)
$$

Para todo $z_{1}, \ldots, z_{d}$. Si $F_{1}\left(z_{1}\right), \ldots, F_{d}\left(z_{d}\right)$ son funciones continuas, entonces se dice que $C$ es única.

Por otra parte, $C$ se define en el $\operatorname{Ran}\left(F_{1}\right) \times \ldots \times \operatorname{Ran}\left(F_{d}\right)$ donde $\operatorname{Ran}\left(F_{i}\right)$ representa al rango de la función $F_{i}$. De igual forma, si $C$ es una cópula y $F_{1}\left(z_{1}\right), \ldots$, $F_{d}\left(z_{d}\right)$ corresponden a funciones de distribuciones univariadas, se dice que la función $F\left(z_{1}, \ldots, z_{d}\right)$ definida previamente constituye una función de distribución conjunta con distribución marginal $F_{1}\left(z_{1}\right), \ldots, F_{d}\left(z_{d}\right)$.

Para la función de distribución multivariada $F$ y sus distribuciones marginales continuas $F_{1}, \ldots, F_{d}$, la cópula $\mathrm{C}$ está definida así:

$$
C\left(u_{1}, \ldots, u_{d}\right)=F\left(F_{1}^{-1}\left(u_{1}\right), \ldots, F_{d}^{-1}\left(u_{d}\right)\right)
$$

Partiendo de $F, F_{1}, \ldots, F_{d}$ y $u_{i}=F\left(z_{i}\right)$ para $i=1, \ldots, d$, se tiene que:

$$
\begin{gathered}
F\left(z_{1}, \ldots, z_{d}\right)=P\left(Z_{1} \leq z_{1}, \ldots, Z_{d} \leq z_{d}\right) \\
=P\left(F_{1}^{-1}\left(Z_{1}\right) \leq F_{1}^{-1}\left(z_{1}\right), \ldots, F_{d}^{-1}\left(Z_{d}\right) \leq F_{d}^{-1}\left(z_{d}\right)\right) \\
=P\left(U_{1} \leq u_{1}, \ldots, U_{d} \leq u_{d}\right) \\
=C\left(u_{1}, \ldots, u_{d}\right)
\end{gathered}
$$

El resultado anterior implica que la cópula descrita es única.

Siguiendo el enfoque de Wang et al. (2010), se seleccionaron tres cópulas para el presente estudio de caso: Gaussiana, $t$-student y Clayton. A continuación, definiremos la función de distribución de las cópulas seleccionadas.

\subsubsection{Cópula Gaussiana}

La cópula Gaussiana o normal hace parte de la familia de cópulas elípticas, donde las distribuciones elípticas principalmente usadas son la normal multivariada 
y la $t$-student (Vose, 2008). La cópula Gaussiana con matriz de correlación $P$ está dada por:

$$
\begin{gathered}
C_{P}^{G a}(u)=\phi_{P}\left(\phi^{-1}\left(u_{1}\right), \ldots, \phi^{-1}\left(u_{d}\right)\right) \\
=\int_{-\infty}^{\phi^{-1}\left(u_{1}\right)} \cdots \int_{-\infty}^{\phi^{-1}\left(u_{d}\right)} \frac{1}{(2 \pi)^{\frac{d}{2}}|\mathrm{P}|^{\frac{1}{2}}} \exp \left(-\frac{1}{2} x^{\prime} \mathrm{P}^{-1} x\right) d x_{1} \ldots d x_{d}
\end{gathered}
$$

donde $\Phi_{P}$ corresponde a la función de distribución normal multivariada cuya matriz de correlación $P \in \mathbb{R}^{a \times a}$ y $\Phi^{-1}$ corresponde a la inversa de la función univariada normal estándar (Cherubini, Luciano y Vecchiato, 2004; Melo y Becerra, 2008).

\subsubsection{Cópula t-student}

La cópula $t$-student hace parte de la familia de cópulas elípticas, y es una cópula que muestra más observaciones en la cola, comparada con la Gaussiana o normal (Wang et al., 2010). La cópula $t$-student con matriz de correlación $P$ viene dada por:

$$
\begin{gathered}
C_{v, P}^{t}(u)=t_{v, P}\left(t_{v}^{-1}\left(u_{1}\right), \ldots, t_{v}^{-1}\left(u_{d}\right)\right) \\
=\int_{-\infty}^{t_{v}^{-1}\left(u_{1}\right)} \ldots \int_{-\infty}^{t_{v}^{-1\left(u_{1}\right)}} \frac{\Gamma\left(\frac{v+d}{2}\right)|\mathrm{P}|^{-\frac{1}{2}}}{\Gamma\left(\frac{v}{2}\right)(v \pi)^{\frac{d}{2}}}\left(1+\frac{1}{v} x^{\prime} \mathrm{P}^{-1} x\right)^{-\frac{v+d}{2}} d x_{1} \ldots d x_{d}
\end{gathered}
$$

Donde la matriz de correlación $P \in \mathbb{R}^{d \times d}$ y la cópula tienen $v>0$ grados de libertad.

$t_{v, P}$ : función de distribución $t$-student multivariada

$t_{v}^{-1}$ : inversa de la función de distribución $t$ asociada a la distribución $t$ univariada 


\subsubsection{Cópula de Clayton}

De acuerdo a Melo y Becerra (2008), la cópula de Clayton, que también es llamada cópula Cook-Johnson o Kimeldorf-Sampson, cuenta con el siguiente generador:

$$
\Phi(t)=\frac{1}{\theta}\left(t^{-\theta}-1\right) \operatorname{con} \theta>0
$$

La función de distribución acumulada de la cópula de Clayton viene dada por:

$$
C^{C l}\left(u_{1}, \ldots, u_{d}\right)=\left(u_{1}^{-\theta}+\ldots+u_{d}^{-\theta}-d+1\right)^{-\frac{1}{\theta}}
$$

\subsection{Cálculo del valor en riesgo y Expected Shortfall}

Melo y Becerra (2005), definen el VaR como el $\alpha$-ésimo percentil de la distribución futura de pérdidas y ganancias. Entonces, dado un periodo de tenencia (t) y un nivel de significancia $(\alpha)$, el $V a R_{\alpha}$ se define como:

$$
\operatorname{VaR}_{\alpha, t}=\inf \left\{r \mid F_{R}(r) \geq \alpha\right\}
$$

donde:

$F_{R}$ : distribución futura de pérdidas y ganancias. $r$ retornos del portafolio o del activo financiero.

Por otra parte, el ES, una medida alternativa al VaR y más conservadora para la medición de riesgos, se define como la pérdida esperada, dado que esta es superior al VaR:

$$
E S_{\alpha, t}=E\left(r \mid r>\operatorname{VaR}_{\alpha}\right)
$$

Si la distribución es continua, Melo y Becerra (2005) definen el ES como: 


$$
E S_{\alpha}=E\left(r \mid r>\operatorname{VaR} R_{\alpha}\right)=\frac{1}{1-F_{R}\left(\operatorname{VaR}_{\alpha}\right)} \int_{\operatorname{VaR}_{\alpha}}^{U} r f_{R}(r) d r
$$

donde:

$U$ : cota superior de los retornos.

$F_{R}$ : función de distribución de los retornos.

$f_{R}$ : función de densidad de los retornos.

Si los retornos tienden a ser normales con media $\mu$ y varianza $\sigma^{2}$, el ES sería equivalente a:

$$
E S_{\alpha}=\mu+\sigma \frac{\phi\left(Z_{\alpha}\right)}{1-\Phi\left(Z_{\alpha}\right)}
$$

donde:

$\phi\left(Z_{\alpha}\right)$ : función de densidad de una variable aleatoria normal estándar. $\Phi\left(Z_{\alpha}\right)$ : función de distribución de una variable aleatoria normal estándar.

$$
Z_{\alpha} \frac{1}{\sigma}\left(V a R_{\alpha}-\mu\right)
$$

$\mu$ : media de los retornos.

\subsubsection{Algoritmo de simulación para el cálculo del VaR y el Expected Shortfall (siguiendo el enfoque de Karmakar, 2017)}

1. Modelar las series de log-retornos usando los modelos ARMA-GARCH para obtener los errores estandarizados y la volatilidad condicional por cada una.

2. Aplicar EVT: fijar un umbral inicial para cada una de las colas, modelar las colas con la GPD y el resto con la distribución empírica o kernel. Calibrar el umbral y, con base en los parámetros de forma y escala, estimar las probabilidades asociadas a los retornos estandarizados. 
3. Obtener la estructura de dependencia conjunta mediante la aplicación de las cópulas Gaussiana, $t$ y Clayton sobre los vectores de probabilidades estimados en 2.

4. Simular por Monte Carlo un escenario de probabilidades correlacionadas para los 5 activos para un día (horizonte de VaR y ES) usando la distribución condicional obtenida mediante las cópulas y obtener los retornos futuros, así:

- Usando la inversa de la función marginal estimada en el punto 2 de la GPD, obtener los residuales estandarizados simulados.

- Tomando los residuales estandarizados del paso 5, pronosticar los retornos esperados a partir de los modelos de las medias y varianzas condicionales del punto 1.

5. Repetir los pasos 4 al 610.000 veces para obtener los 10.000 escenarios de vectores de retornos probables por activo y para los portafolios sugeridos, a saber: un portafolio óptimo sin apalancamiento, uno con apalancamiento y otro de ponderaciones iguales para todos los activos.

6. A partir de los escenarios para los retornos de los portafolios estimados en el punto 7, se calcula el VaR y el ES al 99 y al $95 \%$ de confianza para un horizonte de un día.

\subsection{Pruebas de desempeño o backtesting}

El backtesting permite evaluar el desempeño de las metodologías empleadas para el cálculo del VaR. Se considera que el modelo de medición de riesgos falla cuando el PyG observado excede el valor de la estimación, estas pruebas permiten identificar que el porcentaje de fallos en una ventana de tiempo determinada sea igual al nivel de significancia $(\alpha)$ y que, además, los fallos sean independientes. A continuación, explicaremos dos de las pruebas que permiten identificar lo anterior: el test de Kupiec y el test de Christoffersen.

\subsubsection{Test de Kupiec}

El test de Kupiec, también llamado prueba de proporción de fallas de Kupiec (POF, por sus siglas en inglés), evalúa la hipótesis nula $H_{0}$ donde la probabilidad de fallos es igual a $\alpha$. Por ejemplo, si el VaR es calculado con un nivel de significancia del $1 \%$, se diría que $H_{0}: p=0,01$. Para contrastar la hipótesis nula se emplea una prueba de razón de verosimilitud dada por (Melo y Becerra, 2005): 


$$
L R_{P O F}=-2 \ln \left(\frac{p^{x}(1-p)^{n-x}}{\hat{p}^{x}(1-\hat{p})^{n-x}}\right)
$$

donde:

$x$ : número de excepciones o fallas.

$n$ : número de datos incluidos en el backtesting.

$$
\hat{p}=\frac{x}{n}
$$

Cabe recordar que para esta prueba se contrasta la razón de verosimilitud con la distribución teórica chi-cuadrado con un grado de libertad. Para definir que el modelo tiene un desempeño adecuado, se busca no rechazar la hipótesis nula.

\subsubsection{Test de Christoffersen}

El test de Christoffersen, o test de independencia, evalúa si la probabilidad de que haya una excepción en el periodo presente depende o no de la existencia de una excepción en el periodo pasado. La hipótesis nula $H_{0}$ dice que las probabilidades son independientes. El estadístico que permitiría probar esta hipótesis está dado por:

$$
L R_{\text {ind }}=-2 \log \left(\frac{(1-\pi)^{n 00+n 10} \pi^{n 01+n 11}}{(1-\pi)^{n 00} \pi^{n 01}\left(1-\pi_{1}\right)^{n 10} \pi_{1}^{n 11}}\right)
$$

donde:

n00: número de periodos sin fallos seguidos de un periodo sin fallos.

n10: número de periodos con fallos seguidos de un periodo sin fallos.

n01: número de periodos sin fallos seguidos de un periodo con fallos.

n11: número de periodos con fallos seguidos de un periodo con fallos. 
$\pi_{0}$ : probabilidad de tener una falla en el periodo $t$, dado que no ocurrieron fallas en el periodo $t-1=\frac{n 01}{(n 00+n 01)}$.

$\pi_{1}$ : probabilidad de tener una falla en el periodo $t$, dado que ocurrieron fallas en el periodo $t-1=\frac{n 11}{(n 10+n 11)}$.

$\pi$ : probabilidad de tener una falla en el periodo $t=\frac{n 01+n 11}{(n 00+n 01+n 10+n 11)}$.

Cabe recordar que este estadístico se distribuye chi-cuadrado con 1 grado de libertad. Una medición de riesgo con un desempeño aceptable busca que la probabilidad de que haya un fallo, dado que en el periodo anterior se presentó un fallo, sea igual al nivel de significancia.

Es posible combinar ambas pruebas y obtener el siguiente test de cobertura condicional:

$$
L R_{C C}=L R_{P O F}+L R_{\text {ind }}
$$

El test de cobertura condicional se distribuye asintóticamente chi-cuadrado con 2 grados de libertad.

\section{Datos}

Para efectuar el presente estudio de caso se tomaron 4.240 datos de precios de cierre de cinco monedas latinoamericanas en base dólar: peso colombiano (COP/USD), soles peruanos (PEN/USD), real brasilero (BRL/USD), peso mexicano (MXN/USD) y peso chileno (CLP/USD). Las series de datos empleadas cubrían el rango desde enero del año 2000 hasta septiembre de 2019, y fueron obtenidas de las páginas web de los bancos centrales de cada país. Se tomaron los días bursátiles comunes de los mercados incluidos en el análisis.

Con base en las series de precios se calcularon los retornos logarítmicos para cada una de las cinco divisas. El comportamiento histórico de la serie de precios y de los logretornos y volatilidades se presenta en las figuras 1 y 2 respectivamente. 
Figura 1: Comportamiento histórico de precios para COP/ USD, PEN/USD, BRL/USD, MXN/USD y CLP/USD

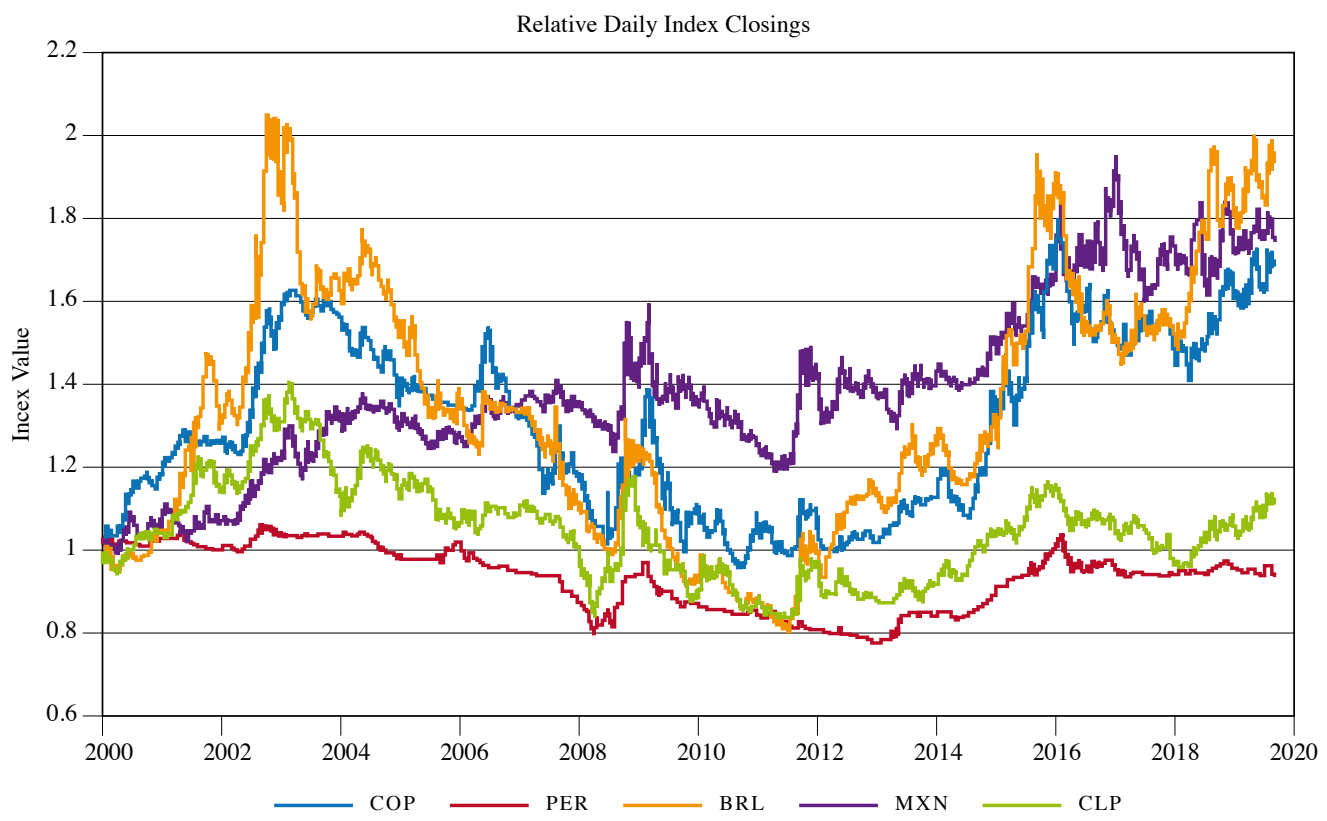

Fuente: elaboración propia.

Figura 2: Retornos y volatilidades históricas para COP/ USD, PEN/USD, BRL/USD, MXN/USD y CLP/USD
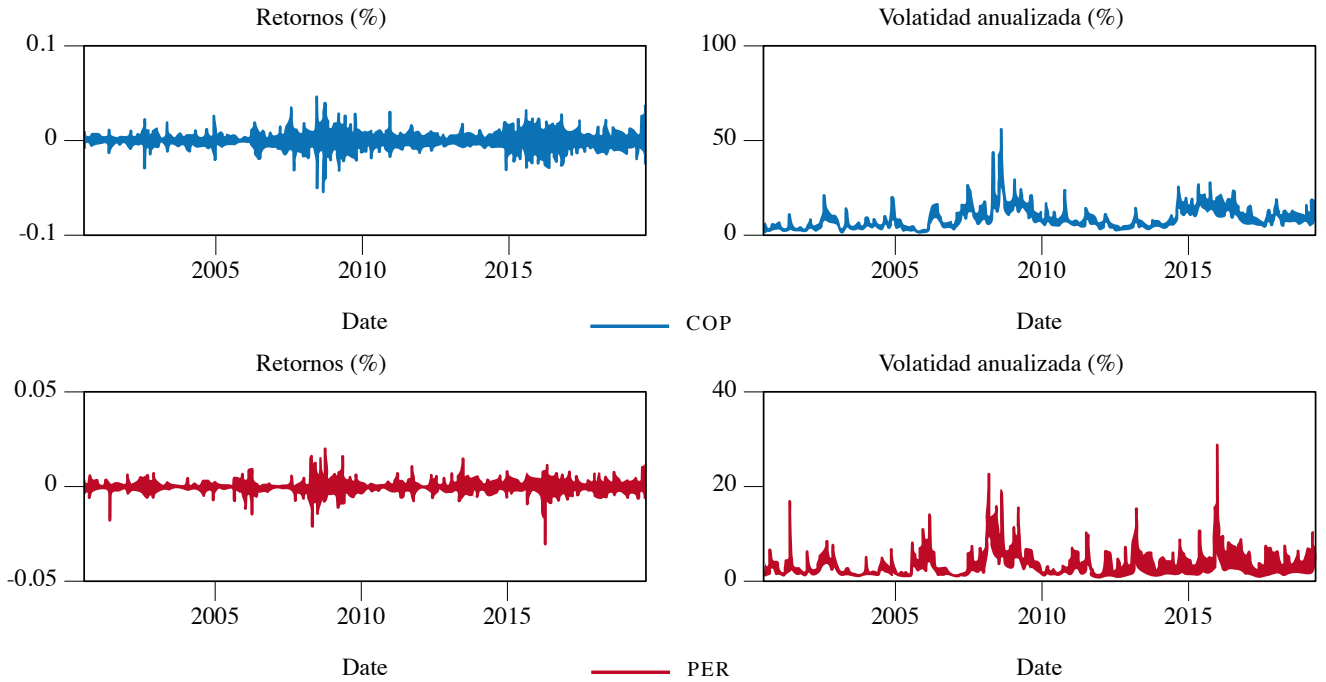

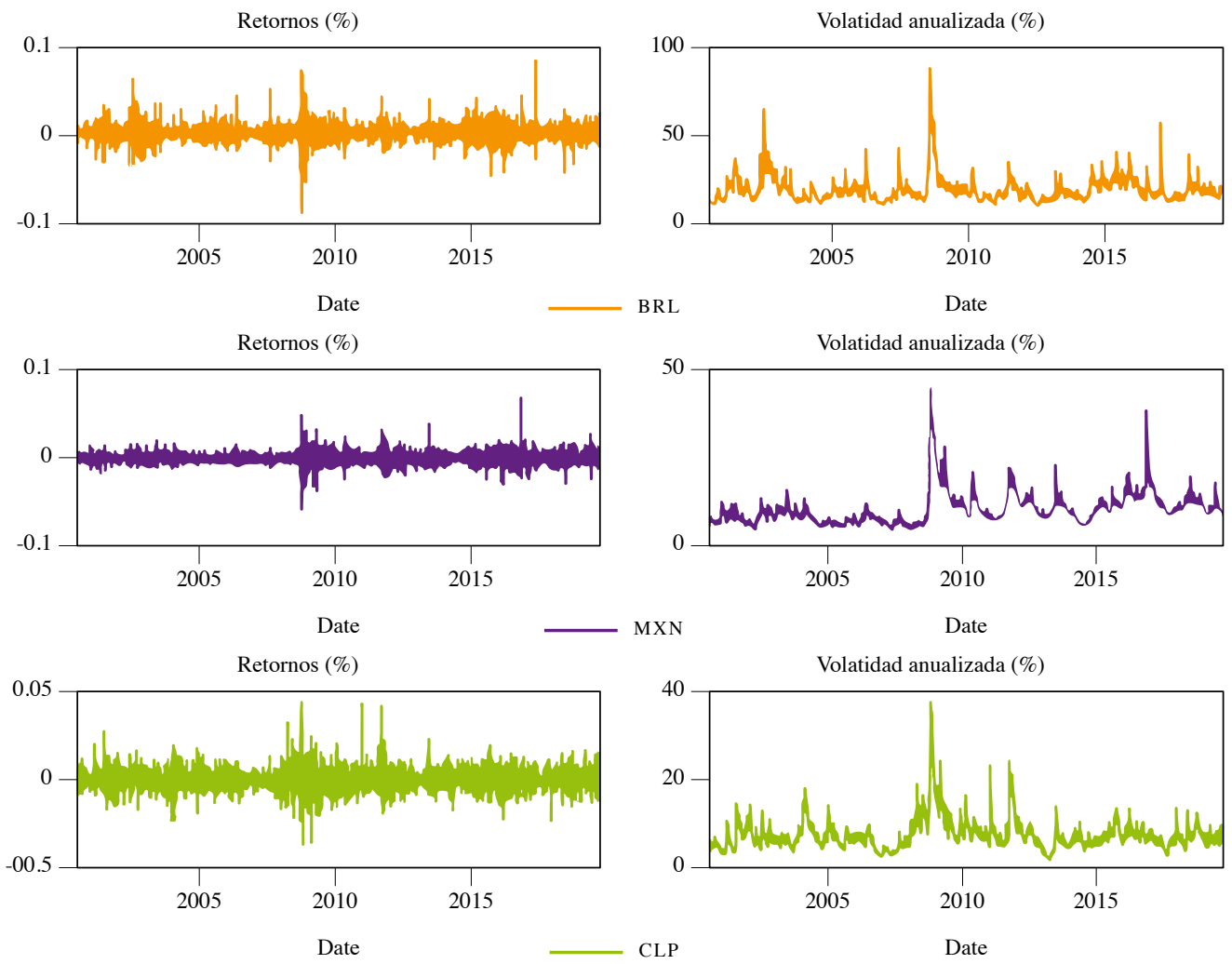

Fuente: elaboración propia.

En los anteriores gráficos sobresalen tres periodos característicos donde se evidencian volatilidades más altas. El primero se identifica en el año 2008, el cual se explica por la crisis subprime que golpeó fuertemente a Estados Unidos y, por ende, a diversos países a nivel mundial, entre ellos los latinoamericanos. El segundo periodo se ubica en 2013, año en el cual se dio el taper tantrum, que inició tras el anuncio de la Reserva Federal de Estados Unidos sobre una posible reducción anticipada de sus compras de bonos. Esto desencadenó caídas fuertes en los tipos de cambio, precios de acciones y bonos de las economías emergentes. El tercer evento se atribuye a la caída de los precios de los commodities (especialmente petróleo) ocurrida después del año 2015, lo que generó una depreciación del peso colombiano cercana al $68 \%$ (Vargas, 2019).

Para las series de logretornos se calcularon los estadísticos descriptivos, que se presentan en la tabla 1. En las pruebas estadísticas realizadas sobre los precios y los logretornos se evidencia, a través del test de Dickey-Fuller Aumentado 
(ADF, por sus siglas en inglés) que todas las series en niveles no presentan estacionariedad, lo cual se puede comprobar al analizar la figura 1. Cuando la misma prueba se efectúa sobre los retornos se obtiene que todas las series son estacionarias, por lo cual los cálculos subsecuentes serán efectuados sobre los retornos lognormales.

El análisis del sesgo nos dice que para tres de las cinco monedas latinoamericanas del portafolio (COP, PEN y BRL) existe asimetría negativa, lo que se traduce en una cola pesada a la izquierda de la media. Esto significa que en Colombia, Perú y Brasil, en los últimos 19 años se han presentado mayor cantidad de episodios de depreciación de la moneda frente al dólar. Por su parte, el peso mexicano y el peso chileno exhiben sesgo positivo, lo que significa que ambas series tienen una cola pesada derecha y mayores episodios de apreciación de su moneda frente al dólar.

En cuanto a la normalidad de las series, el análisis de la prueba Jarque-Bera sugiere el rechazo de la hipótesis nula de normalidad, tanto para niveles como para retornos. Esta tendencia se confirma con la curtosis, que exhibe números muy superiores a 3, lo cual indica que la distribución de los retornos es leptocúrtica con colas más pesadas que las de una distribución normal.

Tabla 1: Estadísticos descriptivos para niveles y retornos del portafolio de monedas escogido

\begin{tabular}{|c|c|c|c|c|c|c|c|c|c|c|c|}
\hline Activo & media & $\begin{array}{c}\text { desv. } \\
\text { Estándar }\end{array}$ & $\min$ & $\max$ & sesgo & curtosis & ADF & P & $\begin{array}{c}\text { Jarque- } \\
\text { bera }\end{array}$ & P \\
\hline \multicolumn{7}{|c|}{ Niveles } \\
\hline COP/USD & $2.370,70$ & 457,80 & $1.652,40$ & $3.477,50$ & 0,42 & 1,95 & 0,82 & 0,89 & 321,58 & 0,00 \\
\hline PEN/USD & 3,20 & 0,29 & 2,50 & 3,70 & $-0,44$ & 1,88 & $-0,21$ & 0,61 & 351,07 & 0,00 \\
\hline BRL/USD & 2,50 & 0,71 & 1,50 & 4,20 & 0,58 & 2,15 & 0,97 & 0,91 & 367,14 & 0,00 \\
\hline MXN/USD & 13,10 & 3,28 & 8,90 & 21,90 & 0,89 & 2,58 & $-2,48$ & 0,34 & 590,11 & 0,00 \\
\hline CLP/USD & 584,30 & 78,18 & 431,20 & 758,20 & 0,18 & 1,81 & 0,48 & 0,82 & 270,43 & 0,00 \\
\hline & & & & & & & & & \\
\hline COP/USD & $0,01 \%$ & $0,69 \%$ & $-5,62 \%$ & $4,80 \%$ & $-0,04$ & 8,82 & $-13,95$ & 0,00 & $5.985,05$ & 0,00 \\
\hline PEN/USD & $0,00 \%$ & $0,26 \%$ & $-3,09 \%$ & $2,06 \%$ & $-0,23$ & 16,63 & $-11,22$ & 0,00 & $32.880,21$ & 0,00 \\
\hline BRL/USD & $0,02 \%$ & $1,03 \%$ & $-9,67 \%$ & $8,67 \%$ & $-0,08$ & 12,29 & $-15,26$ & 0,00 & $15.250,20$ & 0,00 \\
\hline MXN/USD & $0,01 \%$ & $0,67 \%$ & $-5,96 \%$ & $7,01 \%$ & 0,39 & 11,74 & $-64,43$ & 0,00 & $13.609,09$ & 0,00 \\
\hline CLP/USD & $0,00 \%$ & $0,61 \%$ & $-3,80 \%$ & $4,46 \%$ & 0,38 & 7,64 & $-31,73$ & 0,00 & $3.907,84$ & 0,00 \\
\hline
\end{tabular}

Fuente: elaboración propia. 


\section{Resultados}

En esta sección se presentan los resultados empíricos obtenidos con el fin de evaluar el efecto de la inclusión de la estructura de dependencia de los factores de riesgo sobre las mediciones de riesgo de los portafolios propuestos: portafolio óptimo sin apalancamiento, óptimo apalancado y de iguales ponderaciones. En todos los casos, se contempla la misma metodología de modelación de los factores de riesgo; las ponderaciones se tienen en cuenta para evaluar la medición del riesgo en cada uno de los tres portafolios.

En primer lugar, en esta sección se describen los resultados y algunas especificaciones de la modelación de las series univariadas; en segundo lugar, se describe la aplicación de la EVT para la modelación de las colas y los umbrales óptimos obtenidos de este proceso; en tercer lugar, se analizan los resultados obtenidos tras el cálculo del VaR y el Es mediante simulación histórica e incorporando el enfoque EVT-Cópulas, también se evalúan las pruebas de desempeño para cada metodología propuesta.

Los cálculos se efectuaron usando Matlab y, específicamente para la cópula de Clayton, las estimaciones se realizaron empleando un toolbox descargado de la página web de GITHUB, creado por el desarrollador Kiran Karra (Universidad Virginia Tech - EE.UU.).

\subsection{Modelos Univariados - ARMA-GARCH}

Para las cinco series de tipos de cambio de los portafolios se modelaron las distribuciones marginales con el enfoque ARMA-GARCH, siguiendo una distribución normal. En la tabla 2 se presentan los rezagos óptimos que se obtuvieron

Tabla 2: Rezagos óptimos por serie según ACF y PCF

\begin{tabular}{|c|c|c|c|}
\hline \multirow{2}{*}{} & Función de autocorrelación parcial (PCF) & Función de autorrelación simple (ACF) & \\
\cline { 2 - 4 } & $\mathrm{AR}$ & $\mathrm{MA}$ & GARCH \\
\hline COP/USD & 2 & NA & 4,4 \\
\hline PEN/USD & 1 & 2 & 2,2 \\
\hline BRL/USD & $1,4,5$ & $1,4,5$ & 2,3 \\
\hline MXN/USD & $\mathrm{NA}$ & $\mathrm{NA}$ & 2,2 \\
\hline CLP/USD & 3 & 3 & 2,3 \\
\hline
\end{tabular}

Fuente: elaboración propia. 
tras este ejercicio a partir de la evaluación de las funciones de autocorrelación parcial y simple. Las salidas de esta estimación son la volatilidad dinámica condicional (figura 3) y los residuales estandarizados.

Los residuales generados a partir de este proceso fueron analizados para probar la ausencia de autocorrelación serial, se encontró que tras el ajuste por estos rezagos no había presencia de la misma.

Figura 3: Volatilidades condicionales obtenidas de los modelos univariados

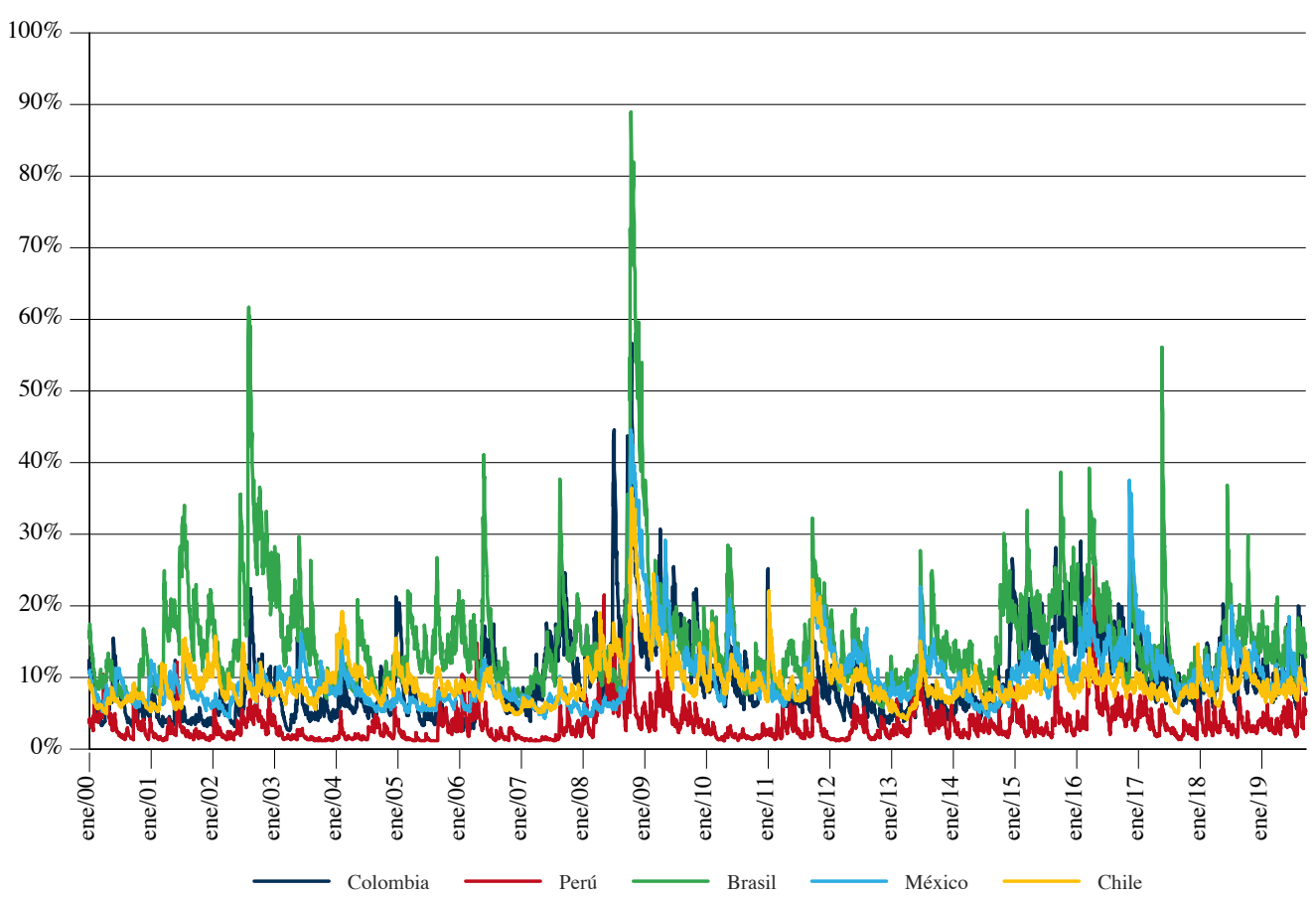

Fuente: elaboración propia.

\subsection{Teoría del valor extremo y distribución generalizada de Pareto}

Para la serie de residuales estandarizados se definió el umbral óptimo a partir de la función de media de los excesos (MEF) y el Hill plot. Para el caso del peso colombiano se pueden apreciar los resultados en la figura 4. Según el criterio del MEF plot, los candidatos a umbral óptimo serán los intervalos donde el exceso de la media de los excesos sigue una tendencia lineal. De acuerdo con el criterio del gráfico de Hill, se escogió el intervalo en el que el parámetro del ajuste 
de la distribución de Pareto fuera estable, es decir que no presentara cambios significativos ante pequeñas variaciones del umbral.

Figura 4: Función de media de los excesos (MEF) y Hill plot para el caso COP/USD (percentiles calibrados)

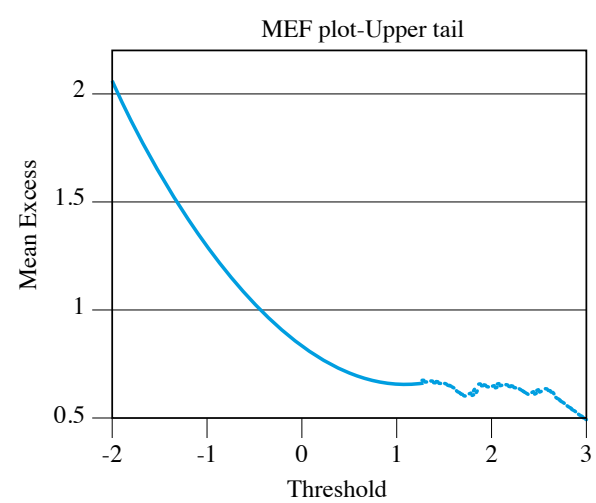

MEF plot-Lower tail

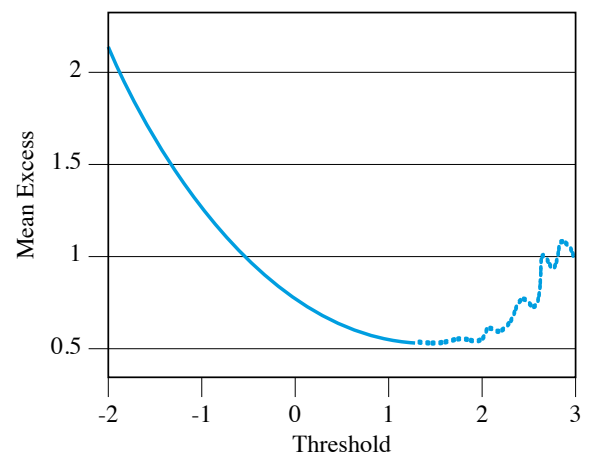

Hill plot-Upper tail

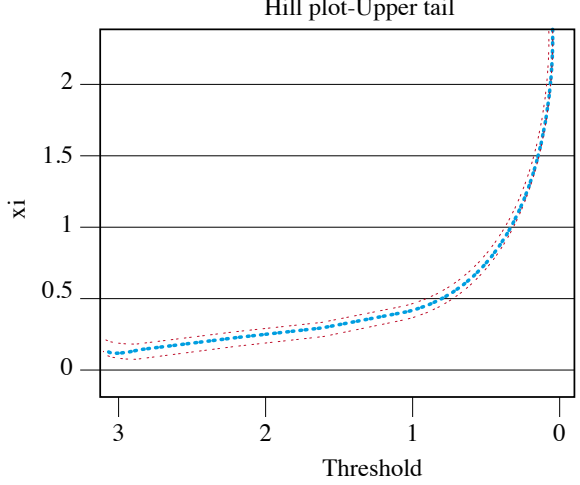

Hill plot-Lower tail

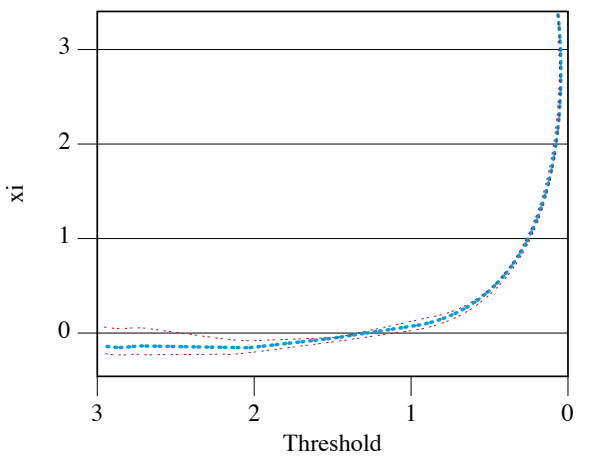

Fuente: elaboración propia.

Para el caso del peso colombiano, usando MEF, se encontró que los rangos óptimos irían de $-2,38,-2,41$ y $-2,58,-2,65$ para la cola izquierda, y de 2,99, 3,11 para la cola derecha. Usando el gráfico de Hill, los intervalos de la cola izquierda serían $-2,16,-2,07 ;-2,34,-2,39$, y para la derecha 3,11 y $-3,27$, por lo que la intersección de ambos criterios arrojó un resultado de -2.385 para la cola izquierda y 3.11 para la cola derecha. Los resultados de este mismo ejercicio para los demás casos se muestran en las tablas 3 y 4 . En la tabla 4 específicamente se muestran los resultados obtenidos de los parámetros estimados y el número de excesos por cola. 
Tabla 3: Cálculo del umbral óptimo

\begin{tabular}{|c|c|c|}
\hline & \multicolumn{2}{|c|}{ Media de los excesos (cambio lineal en el promedio de los excesos respecto al umbral) } \\
\hline & cola izquierda & cola derecha \\
\hline COP/USD & $-2,38,-2,41 ;-2,58,-2,65$ & $2,99,3,11$ \\
\hline PEN/USD & $-2,55,-2,60 ;-3,44,-3,51$ & $2,24,2,37$ \\
\hline BRL/USD & $-1,90,-2,70$ & $1,93,2,3$ \\
\hline MXN/USD & $-2,03,-2,05$ & $2,89,3$ \\
\hline \multirow[t]{3}{*}{ CLP/USD } & $-1,73,-1,77 ;-1,93,-1,95$ & $2,59,2,87$ \\
\hline & \multicolumn{2}{|c|}{ Hill plot (estabilidad del parámetro de forma de Hill) } \\
\hline & cola izquierda & cola derecha \\
\hline COP/USD & $-2,16,-2,07 ;-2,34,-2,39$ & $3,11,-3,27$ \\
\hline PEN/USD & $-1,95,-2,05 ;-2,6,-2,66$ & $2,24,2,4$ \\
\hline BRL/USD & $-2,1,-2,15$ & $1,90,1,95$ \\
\hline MXN/USD & $-1,92,-2,04$ & $1,87,2,4,-2,86$ \\
\hline \multirow[t]{3}{*}{ CLP/USD } & $-1,81,-1,95$ & $2,4,2,6$ \\
\hline & \multicolumn{2}{|c|}{ Intersección } \\
\hline & cola izquierda & cola derecha \\
\hline COP/USD & $-2,38$ & 3,11 \\
\hline PEN/USD & $-2,07$ & 2,52 \\
\hline BRL/USD & $-2,13$ & 1,94 \\
\hline MXN/USD & $-2,04$ & 2,88 \\
\hline CLP/USD & $-1,94$ & 2,60 \\
\hline
\end{tabular}

Fuente: elaboración propia.

Tabla 4: Parámetros obtenidos tras la aplicación de EVT

\begin{tabular}{|l|c|c|c|c|c|}
\hline \multicolumn{7}{|c|}{} & COP/USD & PEN/USD & BRL/USD & MXN/USD & CLP/USD \\
\hline \multicolumn{7}{|c|}{ Cola inferior } \\
\hline Umbral $u^{L}$ & $-2,38156(0,01)$ & $-2,07119(0,02)$ & $-2,12943(0,01)$ & $-2,04505(0,02)$ & $-1,9423(0,03)$ \\
\hline Número de excesos & 46 & 101 & 51 & 55 & 101 \\
\hline
\end{tabular}




\begin{tabular}{|l|c|c|c|c|c|}
\hline & COP/USD & PEN/USD & BRL/USD & MXN/USD & CLP/USD \\
\hline$\xi^{L}$ & 0,474 & 0,108 & 0,027 & $-0,140$ & $-0,097$ \\
\hline$\beta^{L}$ & 0,386 & 0,663 & 0,552 & 0,581 & 0,574 \\
\hline \multicolumn{6}{|c|}{ Cola superior } \\
\hline Umbral $u^{R}$ & $3,11148(0,99)$ & $2,52291(0,98)$ & $1,94143(0,97)$ & $2,8771(0,99)$ & $2,5963(0,99)$ \\
\hline Número de excesos & 16 & 68 & 119 & 32 & 38 \\
\hline$\xi^{R}$ & $-0,155$ & 0,043 & 0,367 & 0,868 & 0,613 \\
\hline$\beta^{R}$ & 0,707 & 0,891 & 0,501 & 0,285 & 0,357 \\
\hline
\end{tabular}

Fuente: elaboración propia.

Tras el ajuste de la calibración de los umbrales en las colas, y usando la distribución empírica en la zona media de la función de densidad acumulada, se llega a la figura 5. En dicha figura se evidencia que el ajuste por Pareto para el caso del COP/USD sigue muy de cerca el comportamiento de la distribución empírica, aunque el ajuste entre las dos colas es más preciso en la cola izquierda (lower tail) que en la derecha (upper tail).

Figura 5: Ajuste de EVT para el caso COP/USD (percentiles 0,10 y 0,90 )
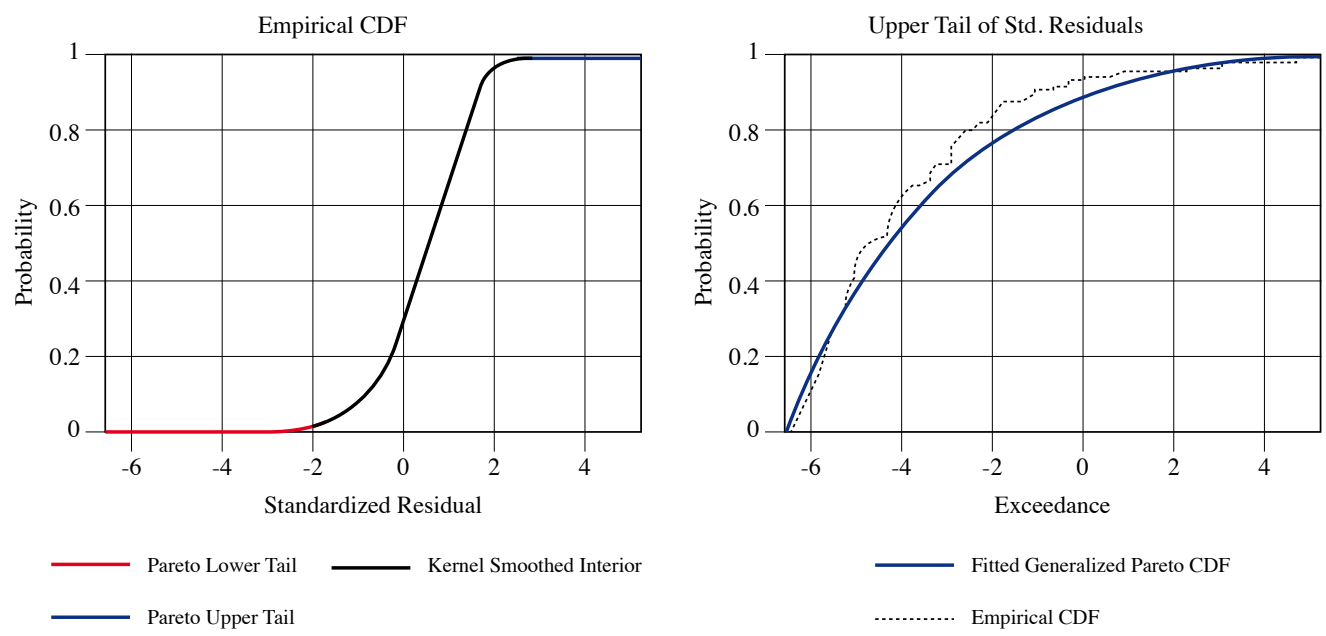


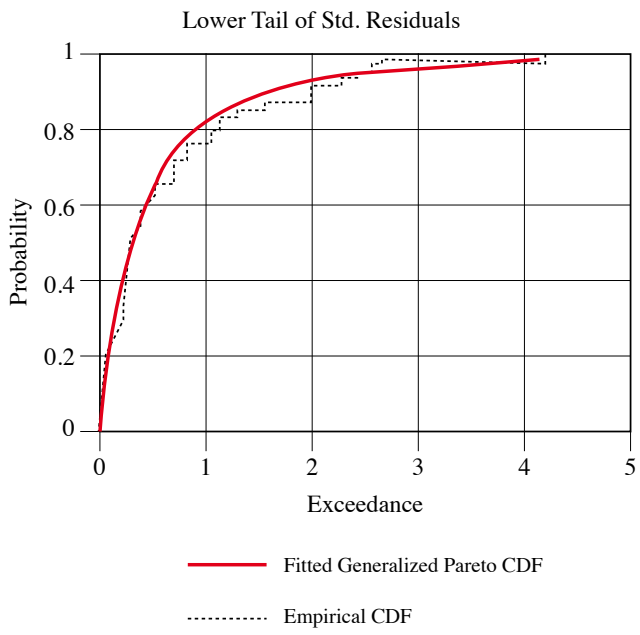

Fuente: elaboración propia.

\subsection{Cálculo del valor en riesgo y Expected Shortfall, y pruebas de desempeño}

El cálculo del VaR y del ES se realizó bajo dos metodologías para tres carteras: portafolio óptimo sin apalancamiento, óptimo con apalancamiento y portafolio con pesos iguales. Las modalidades del cálculo del VaR fueron el método no paramétrico tradicional (simulación histórica) y la simulación de Monte Carlo con los ajustes del enfoque EvT-Cópulas para cada una de las tres cópulas escogidas (Gaussiana, $t$ y Clayton). Con el fin de evaluar el desempeño de cada medición de riesgo propuesta, se calculó el VaR y el Es para los últimos 250 días de la muestra (de agosto de 2018 a septiembre de 2019), y se contrastó contra el PyG diario de cada uno de los portafolios anteriormente mencionados. La recalibración de las ponderaciones de los tres portafolios se hizo diariamente.

Para hallar el portafolio óptimo sin apalancamiento se asumió una rentabilidad objetivo del $5 \%$ EA. Tras la optimización se obtuvo que las mayores asignaciones en la distribución de activos se daban al peso mexicano, seguido del real brasilero y el peso colombiano, lo cual se observa en la figura 6 . 
Figura 6: Ponderaciones para portafolios óptimos sin apalancamiento (para 250 escenarios de backtesting)

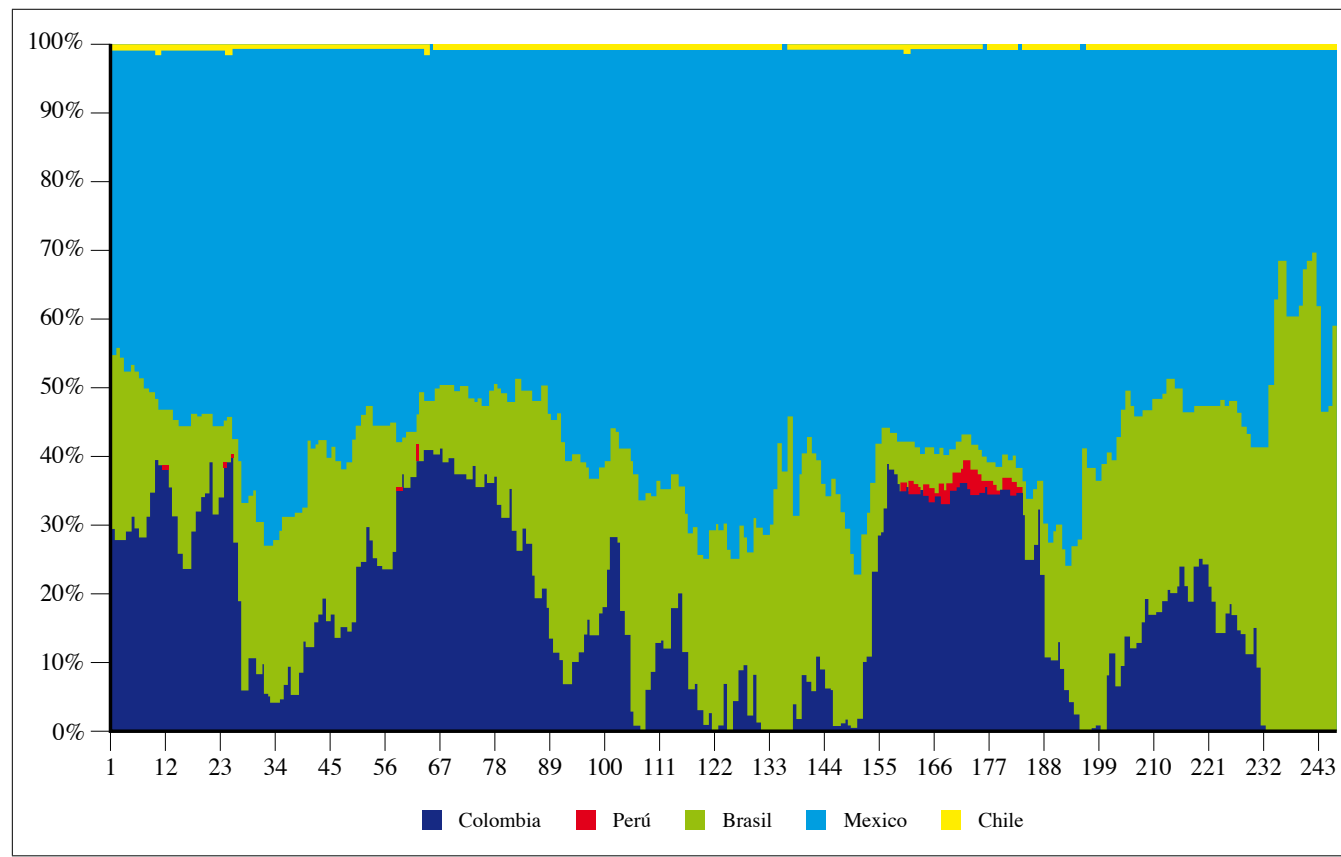

Fuente: elaboración propia.

Para la optimización del portafolio con apalancamiento se asumió una rentabilidad objetivo del $20 \%$ EA, encontrando tras la optimización que, para este caso, el óptimo se obtiene al irse en corto en soles peruanos $(-2 \mathrm{x})^{2}$ y pesos chilenos $(-1 \mathrm{x})$, mientras se manejan posiciones largas en pesos mexicanos $(2 \mathrm{x})$, pesos colombianos $(1,6 \mathrm{x})$ y reales brasileros $(0,4 \mathrm{x})$, lo cual se evidencia gráficamente en la figura 7.

2 La letra $x$ hace referencia al número de veces sobre el nominal del portafolio. Si el portafolio es de USD 100.000, la ponderación en soles peruanos equivaldría a irse corto en USD 200.000. 
Figura 7: Ponderaciones para portafolios óptimos con apalancamiento (para 250 escenarios de backtesting)

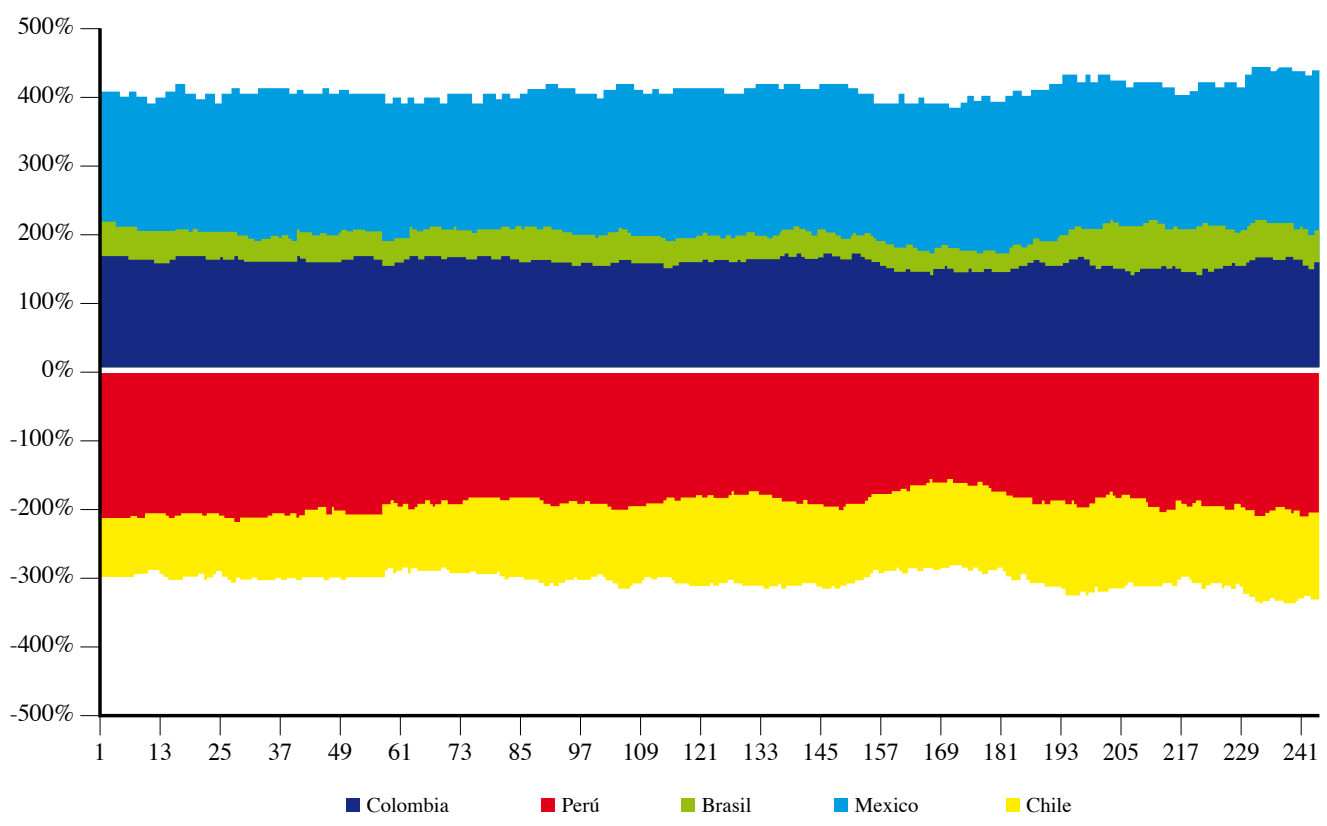

Fuente: elaboración propia.

De la figura 7 se analiza que las mayores ponderaciones largas se dan sobre pesos mexicanos, colombianos y el real brasilero, lo cual se explica por la alta devaluación que han presentado los países, por lo que esta posición le representaría a un inversionista mayores ganancias. Respecto a las demás monedas se aprecia el comportamiento a la inversa, donde una posición corta es más beneficiosa en las monedas de Perú y Chile dado que son las que presentan revaluación (-4,80\% para PER/USD) y el menor nivel de devaluación de la muestra (30,15\% para CLP/USD).

Tras obtener el cálculo del VaR y ES para los tres tipos de portafolios mencionados inicialmente, se aplicaron las pruebas de backtesting a los respectivos resultados, a saber: test de Kupiec, test de Christoffersen y, adicionalmente, la prueba de cobertura condicional o prueba de Kupiec mixta. En la tabla 5 se muestran el porcentaje de fallos y los $p$-valores obtenidos de la prueba de Kupiec para VaR y el ES. El conteo de fallos como medida porcentual es la herramienta más básica del análisis del backtesting y consiste en calcular de manera porcentual las veces que el PyG observado fue menor al VaR, es decir, el porcentaje de 
fallos. Según las pruebas de desempeño con 250 escenarios, todos los modelos de VaR son adecuados tras analizar los $p$-valores de cada prueba para los niveles de confianza (95 y $99 \%)$.

Tabla 5: Porcentaje de fallos para la aplicación del VaR y el ES por método tradicional (simulación histórica) y por Monte Carlo usando enfoque EVT-Cópulas

\begin{tabular}{|c|c|c|c|c|c|c|c|c|c|c|c|c|}
\hline & \multicolumn{12}{|c|}{ Porcentaje de fallos } \\
\hline & \multicolumn{6}{|c|}{ VaR } & \multicolumn{6}{|c|}{ ES } \\
\hline & \multicolumn{2}{|c|}{$\begin{array}{l}\text { Portafolio sin } \\
\text { apalancamiento }\end{array}$} & \multicolumn{2}{|c|}{$\begin{array}{l}\text { Portafolio con } \\
\text { apalancamiento }\end{array}$} & \multicolumn{2}{|c|}{$\begin{array}{c}\text { De iguales } \\
\text { ponderaciones }\end{array}$} & \multicolumn{2}{|c|}{$\begin{array}{l}\text { Portafolio sin } \\
\text { apalancamiento }\end{array}$} & \multicolumn{2}{|c|}{$\begin{array}{l}\text { Portafolio con } \\
\text { apalancamiento }\end{array}$} & \multicolumn{2}{|c|}{$\begin{array}{l}\text { De iguales } \\
\text { ponderaciones }\end{array}$} \\
\hline & $95 \%$ & $99 \%$ & $95 \%$ & $99 \%$ & $95 \%$ & $99 \%$ & $95 \%$ & $99 \%$ & $95 \%$ & $99 \%$ & $95 \%$ & $99 \%$ \\
\hline \multirow{2}{*}{$\begin{array}{l}\text { Simu- } \\
\text { lación } \\
\text { histórica }\end{array}$} & $3,6 \%$ & $0,8 \%$ & $3,6 \%$ & $0,8 \%$ & $4,8 \%$ & $0,8 \%$ & $1,6 \%$ & $0,8 \%$ & $1,2 \%$ & $0,4 \%$ & $2,4 \%$ & $0,4 \%$ \\
\hline & $(0,29)$ & $(0,74)$ & $(0,29)$ & $(0,74)$ & $(0,88)$ & $(0,74)$ & & $(0,74)$ & (0) & $(0,28)$ & $(0,04)$ & $(0,28)$ \\
\hline \multirow{2}{*}{$\begin{array}{l}\text { Montecar- } \\
\text { lo Cópula } \\
\text { Gaussiana }\end{array}$} & $5,6 \%$ & $2 \%$ & $5,2 \%$ & $0,4 \%$ & $6 \%$ & $0,8 \%$ & $3,2 \%$ & $0,8 \%$ & $1,6 \%$ & $0 \%$ & $2 \%$ & $0,8 \%$ \\
\hline & $(0,67)$ & $(0,16)$ & $(0,89)$ & $(0,28)$ & $(0,48)$ & $(0,74)$ & $(0,16)$ & $(0,74)$ & (0) & $(0,02)$ & $(0,01)$ & $(0,74)$ \\
\hline \multirow{2}{*}{$\begin{array}{l}\text { Mon- } \\
\text { tecarlo } \\
\text { Cópula } t\end{array}$} & $5,6 \%$ & $1,2 \%$ & $6,4 \%$ & $0,4 \%$ & $5,2 \%$ & $0,8 \%$ & $3,2 \%$ & $0,8 \%$ & $1,2 \%$ & $0 \%$ & $2 \%$ & $0,8 \%$ \\
\hline & $(0,67)$ & $(0,76)$ & $(0,33)$ & $(0,28)$ & $(0,89)$ & $(0,74)$ & $(0,16)$ & $(0,74)$ & (0) & $(0,02)$ & $(0,01)$ & $(0,74)$ \\
\hline \multirow{2}{*}{$\begin{array}{l}\text { Montecar- } \\
\text { lo Cópula } \\
\text { Clayton }\end{array}$} & $4,8 \%$ & $1,2 \%$ & $6 \%$ & $0,4 \%$ & $4 \%$ & $0,8 \%$ & $2,4 \%$ & $0,4 \%$ & $1,2 \%$ & $0 \%$ & $0,8 \%$ & $0 \%$ \\
\hline & $(0,88)$ & $(0,76)$ & $(0,48)$ & $(0,28)$ & $(0,45)$ & $(0,74)$ & $(0,04)$ & $(0,28)$ & (0) & $(0,02)$ & $(0)$ & $(0,02)$ \\
\hline
\end{tabular}

En paréntesis se encuentra el $p$-valor de la prueba de Kupiec para cada caso.

Fuente: elaboración propia.

El análisis parcial del porcentaje de fallos para el VaR arrojó que para los portafolios óptimos con y sin apalancamiento, las estimaciones por simulación histórica generalmente presentan menor cantidad de fallos que las calculadas por Monte Carlo usando el enfoque EVT-Cópula. Sin embargo, para el portafolio de ponderaciones iguales con un nivel de confianza del $95 \%$ el mejor desempeño se obtiene con el uso de la cópula de Clayton y al $99 \%$ todos los escenarios tienen igual desempeño, evaluado en cantidad de fallos. Esto no es concluyente, dado que según los $p$-valores de las 3 pruebas todos los modelos eran adecuados, pues el número de fallos es estadísticamente igual a los niveles de significancia adoptados (5 y $1 \%$ ). Si se analizan solo los resultados de la 
aproximación EVT-Cópula se encuentra que para los portafolios sin apalancamiento y de iguales ponderaciones los mejores resultados corresponden a los estimados con la cópula de Clayton, mientras que en el portafolio con apalancamiento al $95 \%$ se destaca la Gaussiana, aunque al 99\% todas las cópulas presentan el mismo desempeño. Esta última situación se repite al $99 \%$ en el portafolio de iguales ponderaciones.

De igual forma, se efectuó el backtesting para el cálculo del ES usando los test de Kupiec, Christoffersen y Kupiec mixto para los tres casos de distribución de activos y las cuatro metodologías de obtención de los escenarios del es. Según el test de Kupiec (ver tabla 5), para el portafolio sin apalancamiento al $95 \%$ solo los modelos de Monte Carlo con cópulas Gaussiana y $t$ son adecuados, de acuerdo con el análisis del $p$-valor, mientras que al $99 \%$ todos los modelos son adecuados, siendo el de la cópula de Clayton el modelo que menos porcentaje de fallos tiene. El rechazo de la hipótesis nula en la prueba al $95 \%$ se explica por el bajo nivel de fallos presentado por el modelo de simulación histórica y de cópula de Clayton, dado que la prueba de Kupiec establece un número de fallos mínimos para que los modelos se ubiquen en la zona de no rechazo, y los dos casos presentados, con 4 y 6 fallos respectivamente, no alcanzaron al mínimo número de fallos establecido por la prueba.

Para el portafolio con apalancamiento se repite el rechazo de la hipótesis nula al $95 \%$ y esta vez para todos los casos, por el mismo motivo descrito anteriormente, mientras que al $99 \%$ todos los modelos resultan adecuados, siendo los de cópulas los de mejor desempeño. Por último, para el portafolio de iguales ponderaciones al $95 \%$ se sigue rechazando la hipótesis nula para todos los casos, y al $99 \%$ se presenta el caso contrario, validando todos los modelos y siendo el de la cópula de Clayton el que cuenta con mejor desempeño.

En la tabla 6 se aprecian los $p$-valores de la prueba de Christoffersen o test de independencia para el VaR y el ES, donde todos los $p$-valores confirman el no rechazo de la hipótesis nula, es decir que no hay un patrón predecible para las violaciones del VaR. 
Tabla 6: P-valores de la prueba de independencia de Christoffersen para la aplicación del VaR y el ES por método tradicional (simulación histórica) y por Monte Carlo usando enfoque EVT-Cópulas

\begin{tabular}{|c|c|c|c|c|c|c|c|c|c|c|c|c|}
\hline \multirow[b]{4}{*}{ Nivel de confianza } & \multicolumn{12}{|c|}{ P-valores para Test de Independencia (Christoffersen) } \\
\hline & \multicolumn{6}{|c|}{ VaR } & \multicolumn{6}{|c|}{ ES } \\
\hline & \multicolumn{2}{|c|}{$\begin{array}{l}\text { Portafolio } \\
\text { sin apalan- } \\
\text { camiento }\end{array}$} & \multicolumn{2}{|c|}{$\begin{array}{l}\text { Portafolio } \\
\text { con apalan- } \\
\text { camiento }\end{array}$} & \multicolumn{2}{|c|}{$\begin{array}{c}\text { De iguales } \\
\text { pondera- } \\
\text { ciones }\end{array}$} & \multicolumn{2}{|c|}{$\begin{array}{c}\text { Portafolio } \\
\text { sin apalan- } \\
\text { camiento }\end{array}$} & \multicolumn{2}{|c|}{$\begin{array}{l}\text { Portafolio } \\
\text { con apalan- } \\
\text { camiento }\end{array}$} & \multicolumn{2}{|c|}{$\begin{array}{c}\text { De iguales } \\
\text { pondera- } \\
\text { ciones }\end{array}$} \\
\hline & $95 \%$ & $99 \%$ & $95 \%$ & $99 \%$ & $95 \%$ & $99 \%$ & $95 \%$ & $99 \%$ & $95 \%$ & $99 \%$ & $95 \%$ & $99 \%$ \\
\hline $\begin{array}{l}\text { Simulación } \\
\text { histórica }\end{array}$ & 0,41 & 0,86 & 0,41 & 0,86 & 0,27 & 0,86 & 0,72 & 0,8 & 0,79 & 0,93 & 0,59 & 0,93 \\
\hline $\begin{array}{l}\text { Montecarlo Cópula } \\
\text { Gaussiana }\end{array}$ & 0,81 & 0,65 & 0,23 & 0,93 & 0,92 & 0,86 & 0,2 & 0,8 & 0,72 & $\mathrm{NaN}$ & 0,08 & 0,86 \\
\hline $\begin{array}{l}\text { Montecarlo } \\
\text { Cópula } t\end{array}$ & 0,81 & 0,79 & 0,14 & 0,93 & 0,70 & 0,86 & 0,2 & 0,8 & 0,79 & $\mathrm{NaN}$ & 0,08 & 0,86 \\
\hline $\begin{array}{l}\text { Montecarlo Cópula } \\
\text { Clayton }\end{array}$ & 0,59 & 0,79 & 0,17 & 0,93 & 0,40 & 0,86 & 0,5 & 0,9 & 0,79 & $\mathrm{NaN}$ & 0,86 & $\mathrm{NaN}$ \\
\hline
\end{tabular}

Fuente: elaboración propia.

Para hacer un análisis más a fondo, se calculó la diferencia promedio del VaR y el ES respecto a la pérdida observada para los escenarios en los que se presentaron excepciones, esto con el fin de estudiar si en magnitud se mejora el desempeño cuando se emplea el enfoque EVT-Cópula. En la tabla 7 se evidencia, para el VaR, que en magnitud el ajuste de EVT y cópulas efectivamente ayuda a obtener unas estimaciones de riesgo más cercanas a la realidad observada en todos los casos, a excepción del portafolio de ponderaciones iguales al $95 \%$ de confianza. Sin embargo, en dicho portafolio, cuando se efectúan los cálculos al 99\%, se evidencia que el cálculo con la cópula de Clayton se acerca más a la realidad del PyG observado. Lo anterior indica que ambos modelos son buenos pero que el ajuste por EVT y cópulas nos ayuda a mejorar la estimación de las pérdidas. 


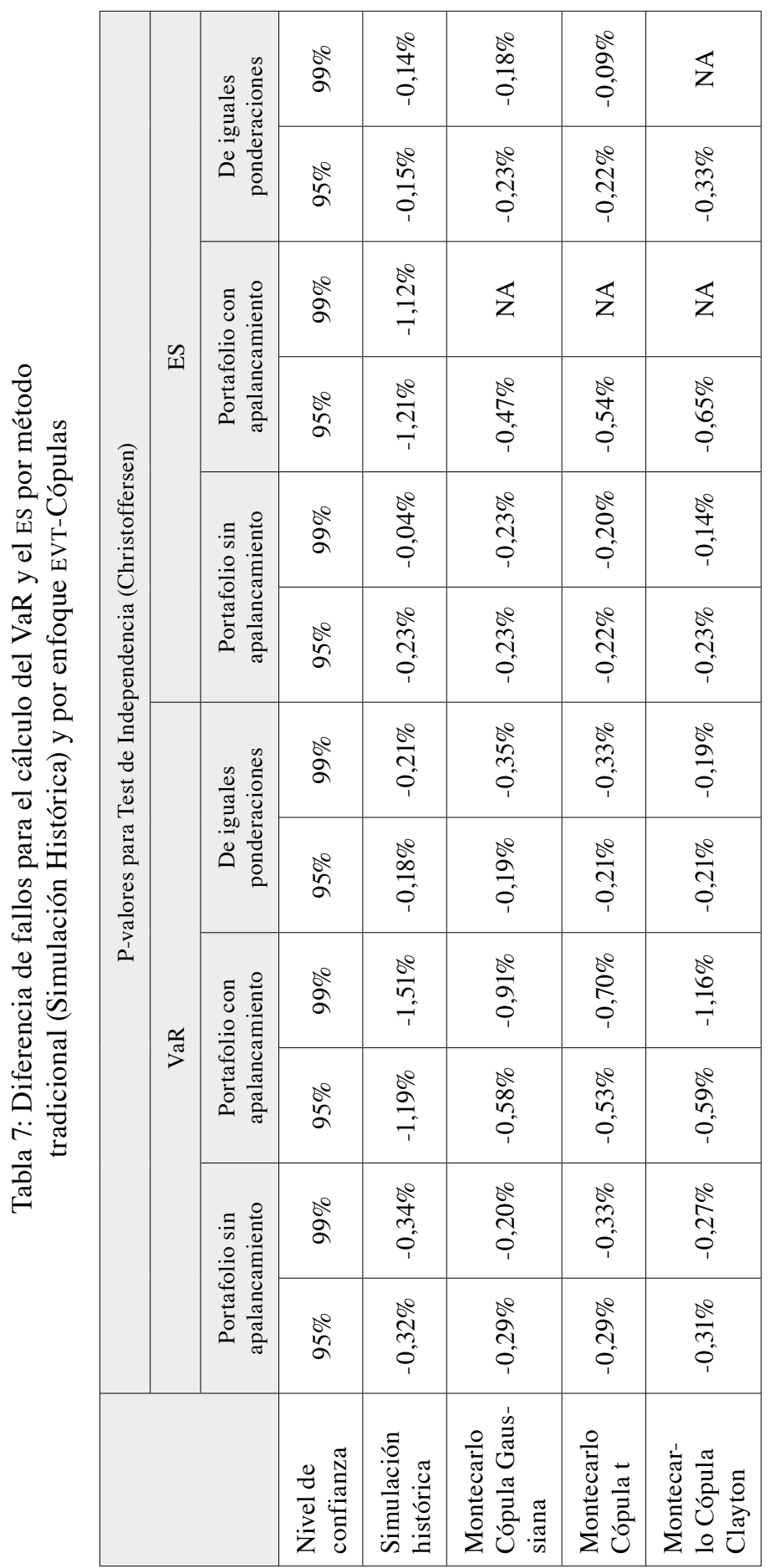

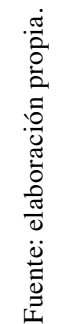


Una comparación inicial entre los resultados de las anteriores tablas, obtenidos para el VaR y el ES, nos dice que mientras en el caso del VaR la introducción del ajuste EVT-Cópula se evidenciaba principalmente en la reducción de la diferencia entre el PyG observado y el VaR estimado, para el caso del ES vemos también una mejora en las pruebas de cobertura (como la de Kupiec).

El análisis de la diferencia promedio de los fallos para el ES (tabla 7) muestra que, en magnitud, el ajuste de EVT y cópulas ayuda reducir la diferencia entre el PyG y el ES al $95 \%$ de confianza para los casos con y sin apalancamiento, donde las cópulas $t$ y gaussiana son las que disminuyen dicha diferencia en mayor medida. Por otra parte, para el caso del portafolio con apalancamiento al $99 \%$ no hay fallos para los tres casos con ajuste de EVT-Cópula. Por último, en presencia de iguales ponderaciones al $95 \%$, la menor diferencia se da para simulación histórica, y al $99 \%$ para la cópula $t$, mientras que para la cópula de Clayton no se presentan fallos.

Comparando los resultados obtenidos del análisis del porcentaje de fallos del VaR con los del ES se encuentra que los porcentajes de fallos son, en promedio, inferiores en el caso del ES comparado con los calculados para el VaR. Asimismo, una cópula no se identifica como la que tenga el mejor desempeño en todos los casos, a todos los niveles de confianza; sin embargo, se aprecia que la cópula de Clayton recurrentemente mejora las estimaciones ya sea medida en porcentaje de excesos o por precisión en la estimación de la pérdida.

Para el caso del VaR, el modelo resulta igual de aceptable en cuanto a desempeño que el caso de simulación histórica; no obstante, cuando se incorpora el ajuste por EVT-Cópulas sí muestra una reducción respecto al PyG observado en los escenarios en los que hay fallos, mientras para el ES el enfoque de cópulas mejora la tolerancia del nivel de cobertura respecto al nivel de significancia, además de reducir la diferencia respecto al PyG observado. La única excepción se da en el portafolio de iguales ponderaciones al 95\%, donde la simulación histórica tiene el mejor desempeño tanto para VaR como para ES. Esto último se puede explicar porque dado que las ponderaciones del portafolio de este caso son iguales, la modelación de las colas puede perder relevancia puesto que se incluye una mayor ponderación en activos menos riesgosos como las monedas de Chile y Perú. 


\section{Conclusiones}

Este artículo buscó analizar si las medidas de desempeño del VaR y el es para un portafolio de monedas de cinco países latinoamericanos mejoran respecto a las mediciones tradicionales de riesgo, tras incorporar un enfoque de EVT y cópulas en la estimación del riesgo.

Luego de aplicar el mencionado ajuste para el cálculo del VaR se encontró que tanto el modelo tradicional como los tres modelos ajustados (cópulas Gaussiana, $t$ y Clayton) eran adecuados según la prueba de Kupiec. Sin embargo, cuando se incorpora el ajuste por EVT y cópulas, la estimación del VaR muestra una reducción de la diferencia respecto al PyG observado para los modelos ajustados en los escenarios en los que hay fallos. En el caso del ES, el enfoque de cópulas mejora tanto la tolerancia del nivel de cobertura respecto al nivel de significancia como la diferencia respecto al PyG observado. La única excepción en cuanto a la diferencia de fallos se da en el portafolio de iguales ponderaciones al $95 \%$, dado que para la simulación histórica el porcentaje de diferencia de fallos es menor tanto para el VaR como para el Es. Esto último se explica porque, al tener el portafolio iguales ponderaciones, la modelación de las colas pierde relevancia cuando se incluye una mayor ponderación en activos menos riesgosos como las monedas de Chile y Perú.

En el análisis del ES se evidencia que al $95 \%$ de confianza para los casos con y sin apalancamiento, las cópulas $t$ y Gaussiana son las que presentan menor diferencia de fallos. Para el caso del portafolio con apalancamiento al $99 \%$ no hay fallos para los tres casos con ajuste de EVT-Cópula. Por último, en presencia de iguales ponderaciones al $95 \%$, la menor diferencia se da para simulación histórica, y al $99 \%$ para la cópula $t$, mientras que para la cópula de Clayton no se presentan fallos. Se resalta que al $95 \%$ para el ES, la baja cantidad de fallos hace que solo los modelos de Monte Carlo, con cópulas Gaussiana y $t$, se muestren como adecuados a la luz de la prueba de Kupiec para el portafolio sin apalancamiento, mientras que al $99 \%$ todos los modelos son adecuados. Para el portafolio con apalancamiento se repite el rechazo de la hipótesis nula al $95 \%$, pero para todos los casos -también por baja cantidad de fallos-, mientras que al $99 \%$ todos los modelos resultan adecuados destacándose los de cópulas como los de mejor desempeño.

Uno de los hallazgos más interesantes de este estudio es que para el caso del VaR, la introducción del ajuste EVT-Cópula mejoraba principalmente la diferencia entre el PyG observado y el VaR estimado, mientras que para el caso del Es se 
aprecia una mejora tanto en las pruebas de cobertura como en la reducción de la diferencia de fallos.

Por otra parte, se identificó a la cópula de Clayton como la que recurrentemente mejora las estimaciones cuando se evalúa por porcentaje de excesos o por precisión en la estimación de la pérdida.

Para trabajos complementarios a futuro se sugiere realizar el mismo análisis de desempeño para horizontes superiores a un día, puesto que a veces la calibración de los pesos de los portafolios y su ajuste se hace a estos horizontes, dependiendo de sus gestores.

\section{Referencias}

Acerbi, C. y Tasche, D. (2002). On the coherence of expected shortfall. Journal of Banking and Finance, 26(7), 1487-1503. https://doi.org/10.1016/S0378-4266(02)00283-2

Alba Suárez, M. A., Pineda-Ríos, W. y Deaza Chaves, J. (2019). Análisis comparativo de las metodologías de estimación semiparamétricas y vía cópulas del valor en riesgo (VaR) en el mercado accionario colombiano. Revista Mexicana de Economía y Finanzas Nueva Época, 14(2), 279-307.

Artzner, P., Delbaen, F., Eber, J.-M. y Heath, D. (1998). Coherent measures of risk. Mathematical Finance, 9(June 1996), 1-24.

Balkema, A. A. y De Haan, L. (1974). Residual life time at great age. The Annals of Probability, 2(5), 792-804. Recuperado de http://projecteuclid.org/euclid. aop/1176996548

Bob, N. K. (2013). Value at Risk Estimation. A GARCH- EVT-Copula Approach (Master Thesis in Mathematical) Statistics Matematiska institutionen.

Bollerslev, T. (1986). generalized autoregressive conditional heteroskedasticity while conventional time series and econometric models operate under an assumption of constant variance, the ARCH (Autoregressive Conditional Heteroskedastic) process introduced in Engle (1982). Journal of Econometrics, 31, 307-327.

Ceballos, A. M. (2015). Implementación de cópulas para la estimación del Valor en Riesgo. Universidad del Rosario, Facultad de Economía. 
Cherubini, U., Luciano, E. y Vecchiato, W. (2004). Copula methods in Finance. John Wiley \& Sons.

Coles, S. (2001). An Introduction to Statistical Modeling of Extreme Values. SpringerVerlag London Limited.

Danielsson, J., Haan, L. De, Peng, L. y De Vries, C. G. (2001). Using a bootstrap method to choose the sample fraction in tail index estimation. Journal of Multivariate Analysis, 248(76), 226-248.

Di Clemente, A. y Romano, C. (2005). Measuring portfolio value-at-risk by a CopulaEVT based approach. Studi Economici, 85(January), 1-22.

Embrechts, P. (2000). Extreme value theory: Potential and limitations as an integrated risk management tool. Derivative Use, Trading \& Regulation, (6), 449-456.

Embrechts, P., Kluppelberg, C. y Mikosch, T. (1996). Modelling Extremal Events for Insurance and Finance. Springer.

Embrechts, P., McNeil, A. J. y Straumann, D. (2002). Correlation and dependence in risk management: Properties and pitfalls. En M. A. H. Dempster (ed.), Risk Management. Cambridge: Cambridge University Press. https://doi.org/10.1017/ cbo9780511615337.008

Engle, R. F. (1982). Autoregressive conditional heteroscedasticity with estimates of the variance of United Kingdom inflation. Econometrica, 50(4), 987-1007. https:// doi.org/10.2307/1912773

Feo Cediel, Y. (2016). Regular Vine Cópulas: una aplicación al cálculo de valor en riesgo. Revista de Investigación en Modelos Financieros, 2(II), 30-64.

Fernández, V. (2008). Copula-based measures of dependence structure in assets returns. Physica A: Statistical Mechanics and Its Applications, 387(14), 3615-3628. https:// doi.org/10.1016/j.physa.2008.02.055

Hotta, L. K., Lucas, E. C. y Palaro, H. P. (2008). Estimation of VaR using copula and extreme value theory. Multinational Finance Journal, 12(3/4), 205-218. https:// doi.org/10.17578/12-3/4-3 
Hsu, C.-P., Huang, C.-W. y Chiou, W.-J. P. (2011). Effectiveness of copula-extreme value theory in estimating value-at-risk: Empirical evidence from Asian emerging markets. Review of Quantitative Finance and Accounting, 39, 447-468. https:// doi.org/10.1007/s11156-011-0261-0

Hussain, S. I. y Li, S. (2018). The dependence structure between Chinese and other major stock markets using extreme values and copulas. International Review of Economics and Finance, 56(February 2016), 421-437. https://doi.org/10.1016/j. iref.2017.12.002

J.P. Morgan/Reuters (1996). RiskMetrics - Technical Document. Morgan Guaranty Trust Company Risk Management Advisory.

Karmakar, M. (2017). Dependence structure and portfolio risk in Indian foreign exchange market: A GARCH-EVT-Copula approach. Quarterly Review of Economics and Finance, 64, 275-291. https://doi.org/10.1016/j.qref.2017.01.007

Kole, E., Koedijk, K. y Verbeek, M. (2007). Selecting copulas for risk management. Journal of Banking and Finance, 31(8), 2405-2423. https://doi.org/10.1016/j. jbankfin.2006.09.010

Koliai, L. (2016). Extreme risk modeling: An EVT-pair-copulas approach for financial stress tests. Journal of Banking and Finance, 70, 1-22. https://doi.org/10.1016/j. jbankfin.2016.02.004

Lee, S. Y. y Kim, J. H. T. (2017). Exponentiated generalized Pareto distribution: Properties and applications towards Extreme Value Theory. Communications in Statistics - Theory and Methods, August.

Loaiza, R., Gómez-González, J. E. y Melo, L. F. (2015). Latin American exchange rate dependencies: A regular vine copula approach. Contemporary Economic Policy, 33(3), 535-549. https://doi.org/10.1111/coep.12091

McNeil, A. J. (1999). Extreme Value Theory for Risk Managers. A general introduction to extreme risk. Internal Modelling and CAD II, 3, 1-22. Recuperado de http:// scholar.google.com/scholar?hl=en\&btnG=Search\&q=intitle:Extreme+Value+T heory+for+Risk+Managers\#0 
McNeil, A. J. y Frey, R. (2000). Estimation of tail-related risk measures for heteroscedastic financial time series: An extreme value approach. Journal of Empirical Finance, 7, 271-300.

McNeil,A. J., Frey, R. y Embrechts, P. (2005). Quantitative Risk Management: Concepts, Techniques and Tools. Princeton University Press.

Melo, L. F. y Becerra, O. (2005). Medidas de riesgo, caracteristicas y tecnicas de medicion: una aplicacion del VaR y el ES a la tasa interbancaria de Colombia. Universidad del Rosario. Universidad del Rosario. Recuperado de https://repository.urosario.edu.co/handle/10336/1060

Melo, L. F. y Becerra, O. (2008). Medidas de riesgo financiero usando cópulas: Teoría y aplicaciones Borradores de Economia, 489(4), 93. Recuperado de http://www. banrep.gov.co/docum/ftp/borra489.pdf

Nystrom, K. y Skoglund, J. (2002). Univariate extreme value theory, garch and measures of risk. Swedbank.

Palaro, H. P. y Hotta, L. K. (2006). Using conditional copula to estimate value at risk. Journal of Data Science, 4, 93-115.

Patton, A. J. (2006). Modelling asymmetric exchange rate dependence. International Economic Review, 47(2), 527-556.

Pickands, J. (1975). Statistical inference using extreme order statistics. The Annals of Statistics, 3(1), 119-131.

Quevedo, A. R. (2005). Dependencia entre activos financieros: Un ejemplo para la relación TES-dólar más allá de los supuestos. Odeon, 2(1).

Salinas, S. M., Maldonado, D. A. y Díaz, L. G. (2010). Estimación del riesgo en un portafolio de activos. Revista Apuntes del CENES, 29(50), 117-150.

Sklar, A. (1959). Fonctions de répartition àn dimensions et leurs marges. Publications de l'Institut de Statistique de l'Université de Paris, 8, 229-231.

Torres Avendaño, G. I. y Olarte Cadavid, A. M. (2009). Valor en riesgo desde un enfoque de cópulas. AD-Minister Universidad EAFIT, 15, 113-136. 
Triana, D., Torres, L. M., Alba, M. A. y Pineda-Ríos, W. (2018). Estimación Bayesiana para el cálculo del Valor en Riesgo (VaR) en modelos de series financieras con relaciones de dependencia no lineal en Colombia.Comunicaciones en Estadística, 11(2), 171-189.

Uribe, J. y Ulloa, I. (2012). La medición del riesgo en eventos extremos. Una revisión metodológica en contexto. Lecturas de Economía (76), 87-117.

Vargas, A. C. (2019). Asymmetric Volatility Spillovers of Financial Markets : An Application to Colombia. Bogotá: Universidad Nacional de Colombia.

Vose, D. (2008). A quantitative guide (3 ed.). Chichester: John Wiley \& Sons.

Wang, Z., Jin, Y. y Zhou, Y. (2010). Estimating portfolio risk using GARCH-EVT-copula model: An empirical study on exchange rate market. Lecture Notes in Electrical Engineering, 67 LNEE, 65-72. https://doi.org/10.1007/978-3-642-12990-2_8

Wang, Z. R., Chen, X. H., Jin, Y. B. y Zhou, Y. J. (2010). Estimating risk of foreign exchange portfolio: Using VaR and CVaR based on GARCHEVT-Copula model. Physica A: Statistical Mechanics and Its Applications, 389(21), 4918-4928. https:// doi.org/10.1016/j.physa.2010.07.012

Yamai, Y. y Yoshiba, T. (2002). Comparative analyses of Expected Shortfall and Valueat-Risk: Their estimation error, decomposition, and optimization. Comparative Analyses of Expected Shortfall and Value-at-Risk, 20(1), 87-121.

Yamai, Y. y Yoshiba, T. (2005). Value-at-risk versus expected shortfall: A practical perspective. Journal of Banking and Finance, 29(4), 997-1015. https://doi. org/10.1016/j.jbankfin.2004.08.010

Yu, W., Yang, K., Wei, Y. y Lei, L. (2018). Measuring Value-at-Risk and Expected Shortfall of crude oil portfolio using extreme value theory and vine copula. Physica A: Statistical Mechanics and Its Applications, 490, 1423-1433. https:// doi.org/10.1016/j.physa.2017.08.064 


\section{Anexo}

Figura 1: Ajuste de EVT para el caso BRL/USD (percentiles 0,10 y 0,90 )

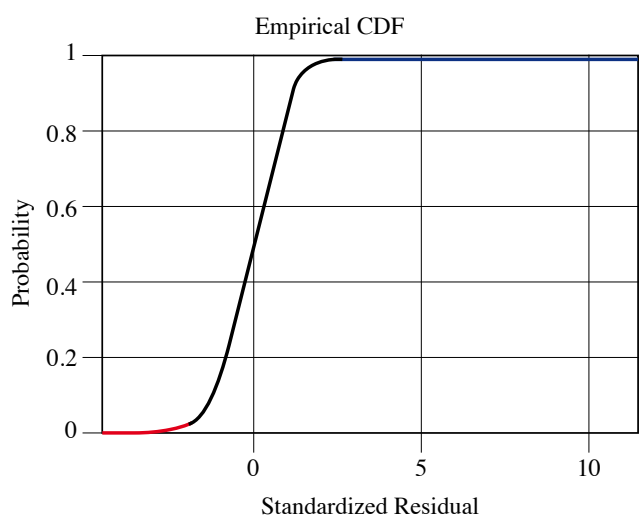

Pareto Lower Tail

Pareto Upper Tail

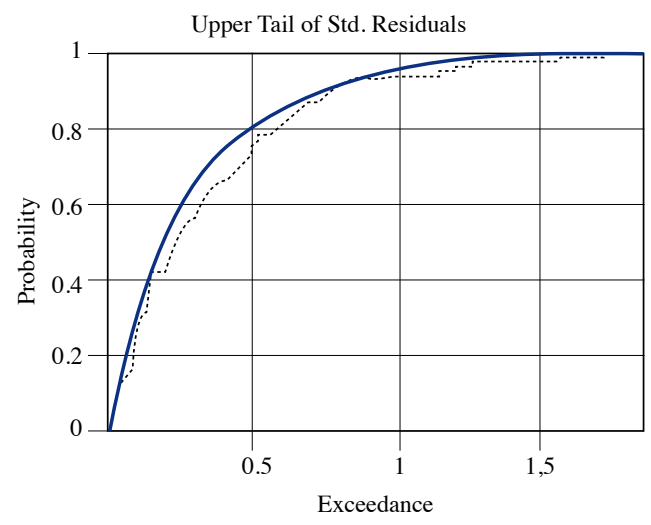

Fitted Generalized Pareto CDF Empirical CDF

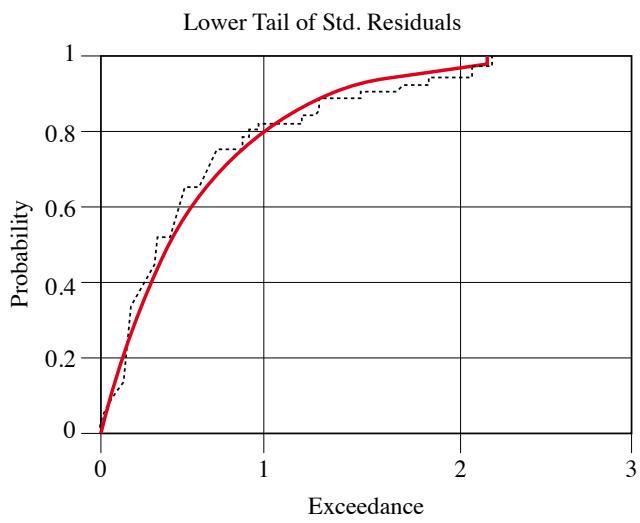

- Fitted Generalized Pareto CDF

Empirical CDF

Fuente: elaboración propia. 
Figura 2: Ajuste de EVT para el caso CLP/USD (percentiles 0,10 y 0,90)

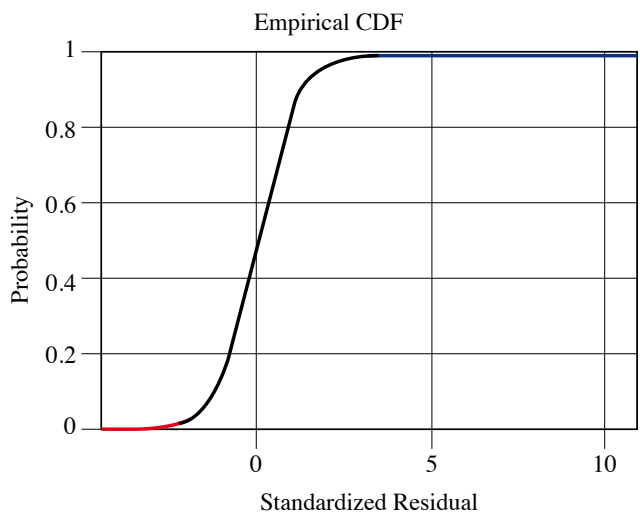

Pareto Lower Tail Pareto Upper Tail

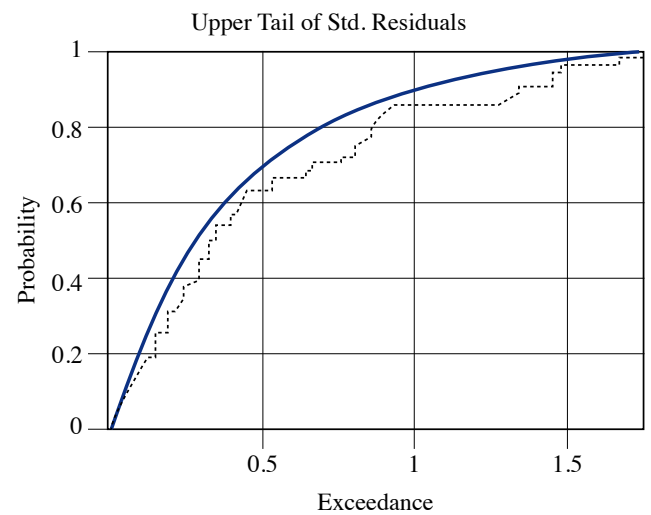

Fitted Generalized Pareto CDF

Empirical CDF

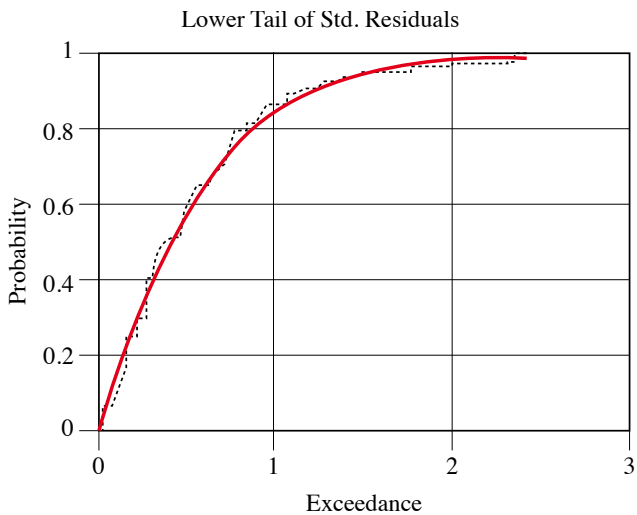

Fitted Generalized Pareto CDF

Empirical CDF

Fuente: elaboración propia. 
Figura 3: Ajuste de EVT para el caso PER/USD (percentiles 0,10 y 0,90 )

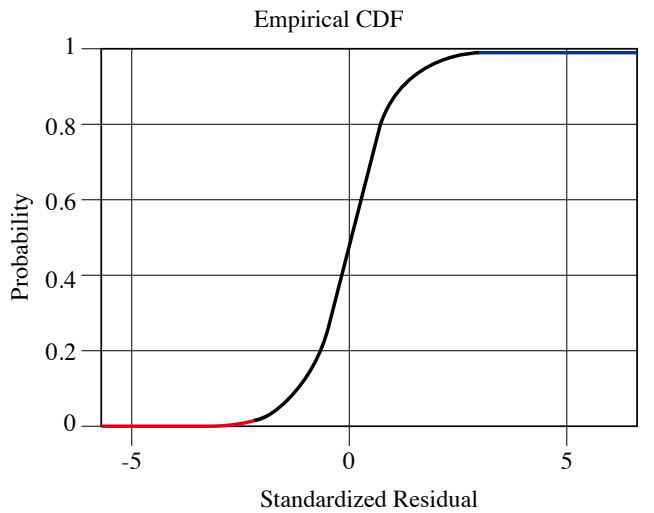

Pareto Lower Tail

Pareto Upper Tail

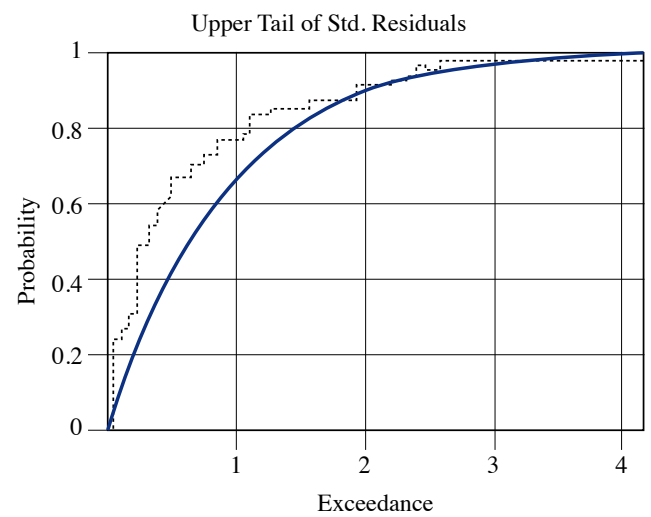

Fitted Generalized Pareto CDF

Empirical CDF

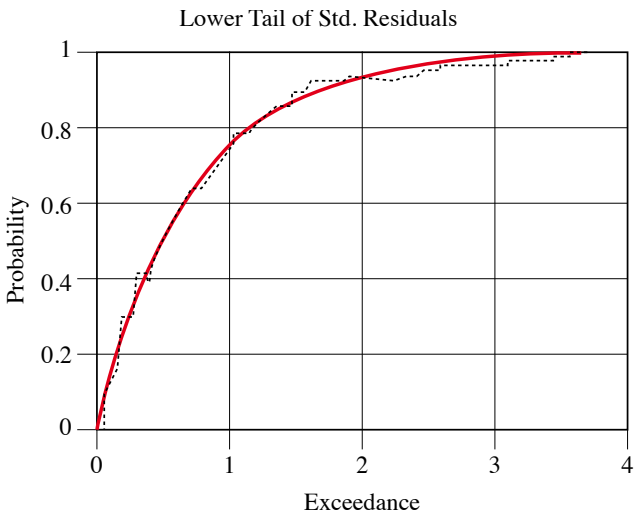

Fitted Generalized Pareto CDF

Empirical CDF

Fuente: elaboración propia. 
Figura 4: Ajuste de EVT para el caso MXN/USD (percentiles 0,10 y 0,90)

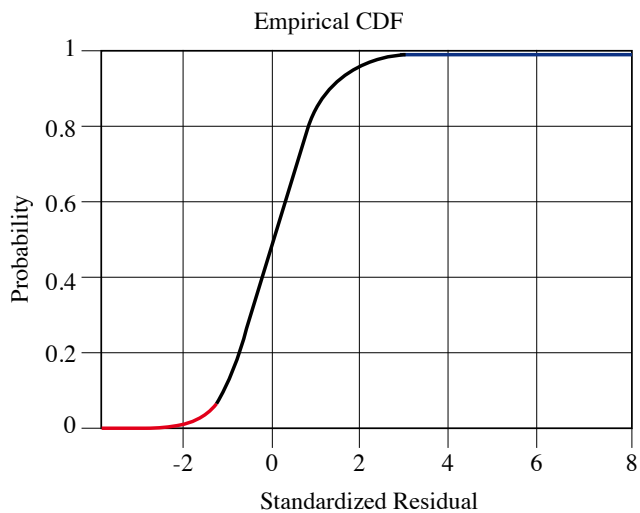

Pareto Lower Tail

Pareto Upper Tail

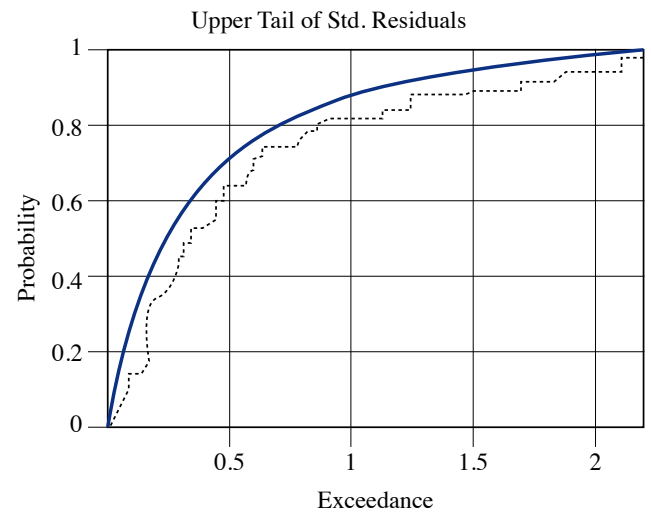

Fitted Generalized Pareto CDF

Empirical CDF

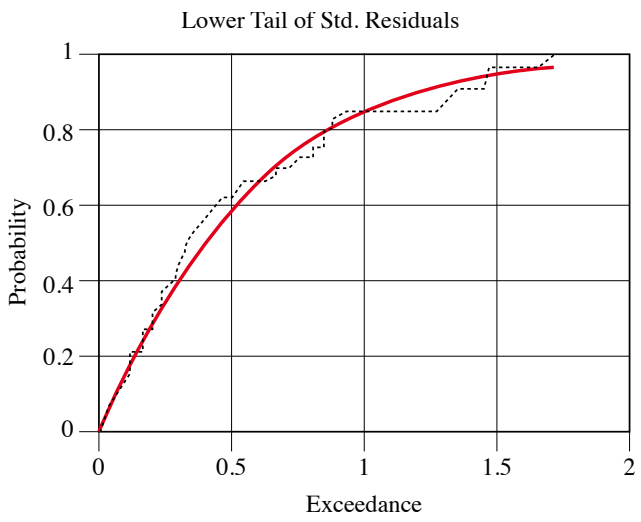

Fitted Generalized Pareto CDF

Empirical CDF

Fuente: elaboración propia. 
Figura 5: Contraste del VaR contra PyG observado para la cópula Clayton
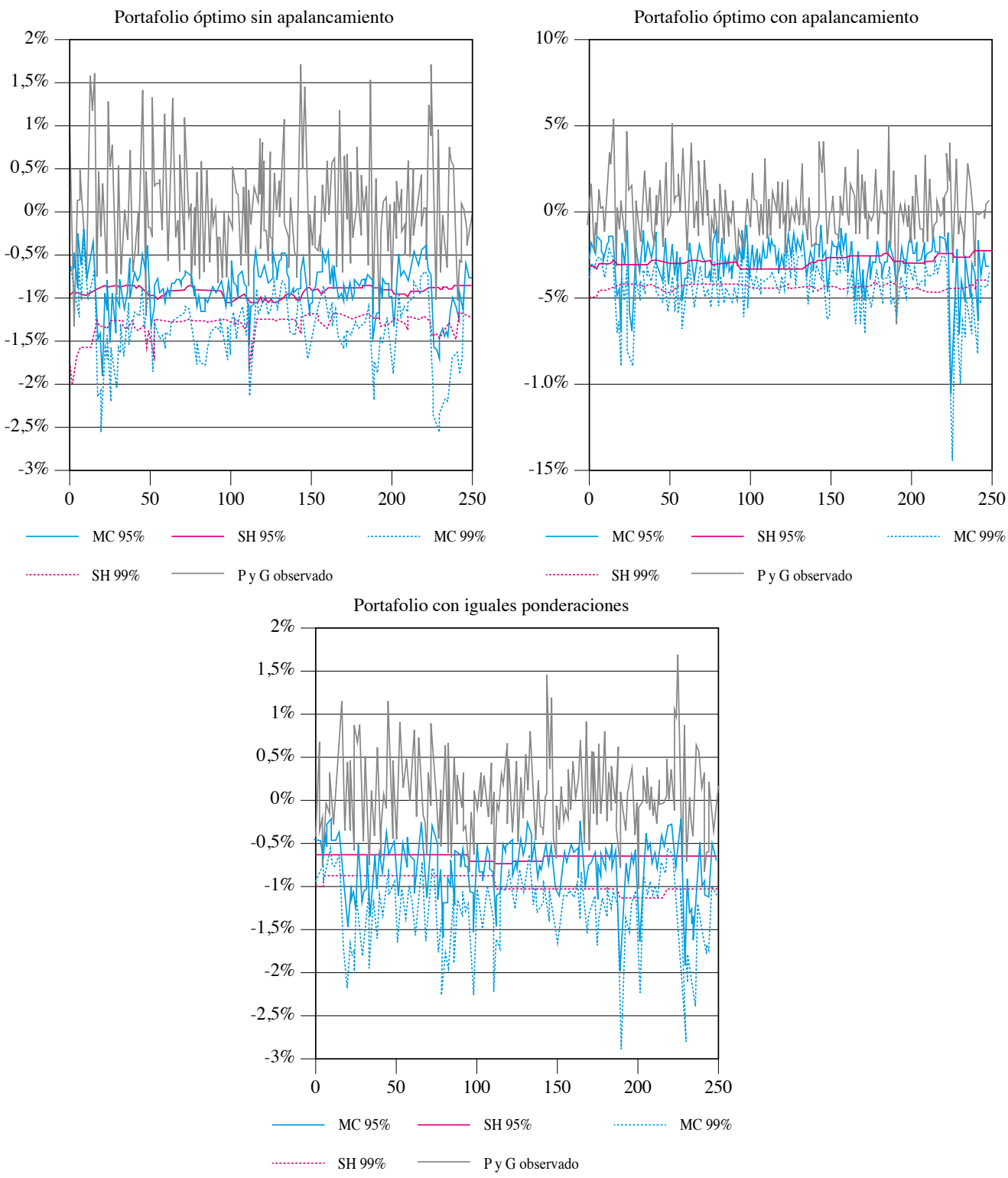

Fuente: elaboración propia. 
Figura 6: Contraste del VaR contra PyG observado para la cópula Gaussiana
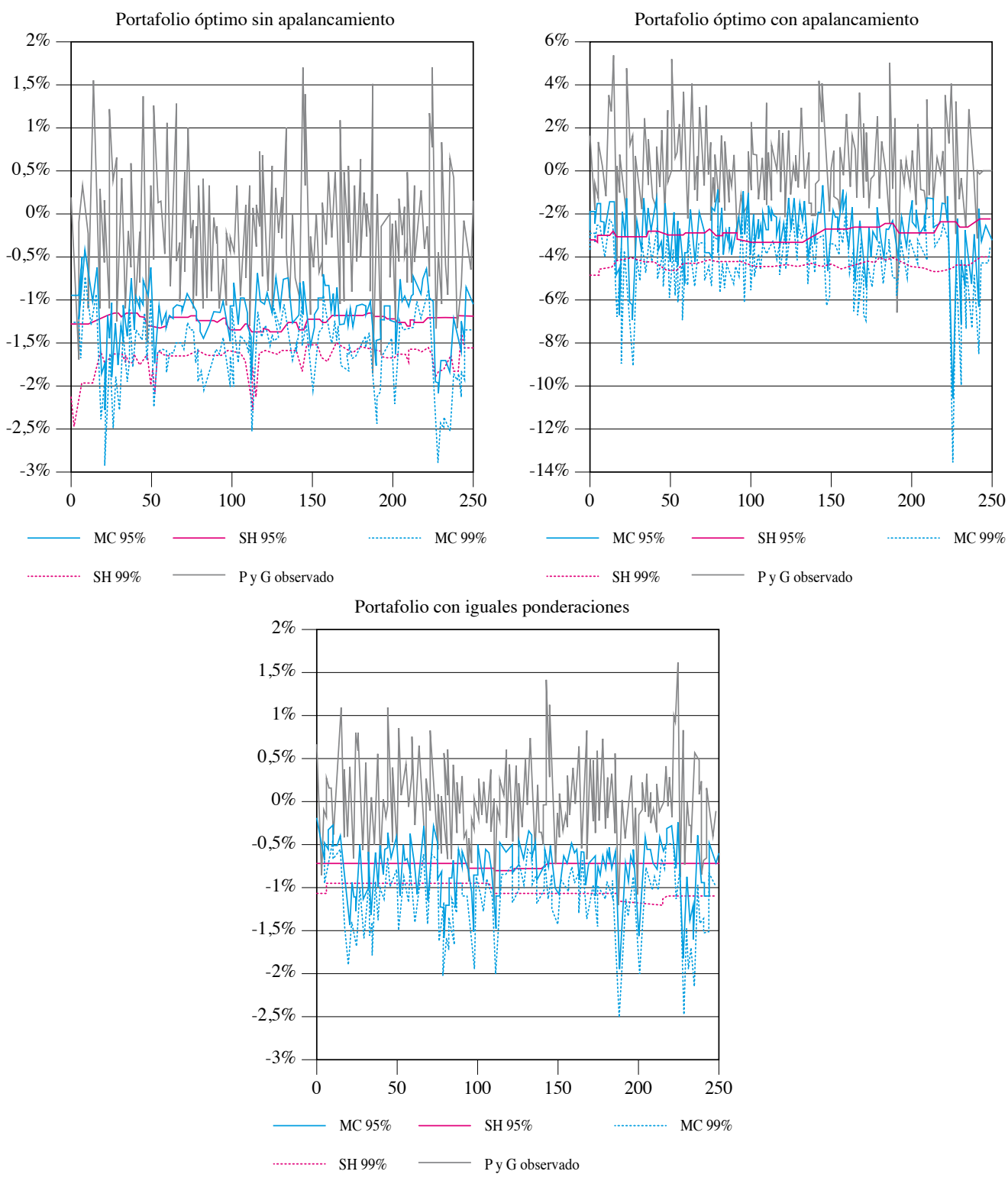

Fuente: elaboración propia. 
Figura 7: Contraste del VaR contra PyG observado para la cópula t-student
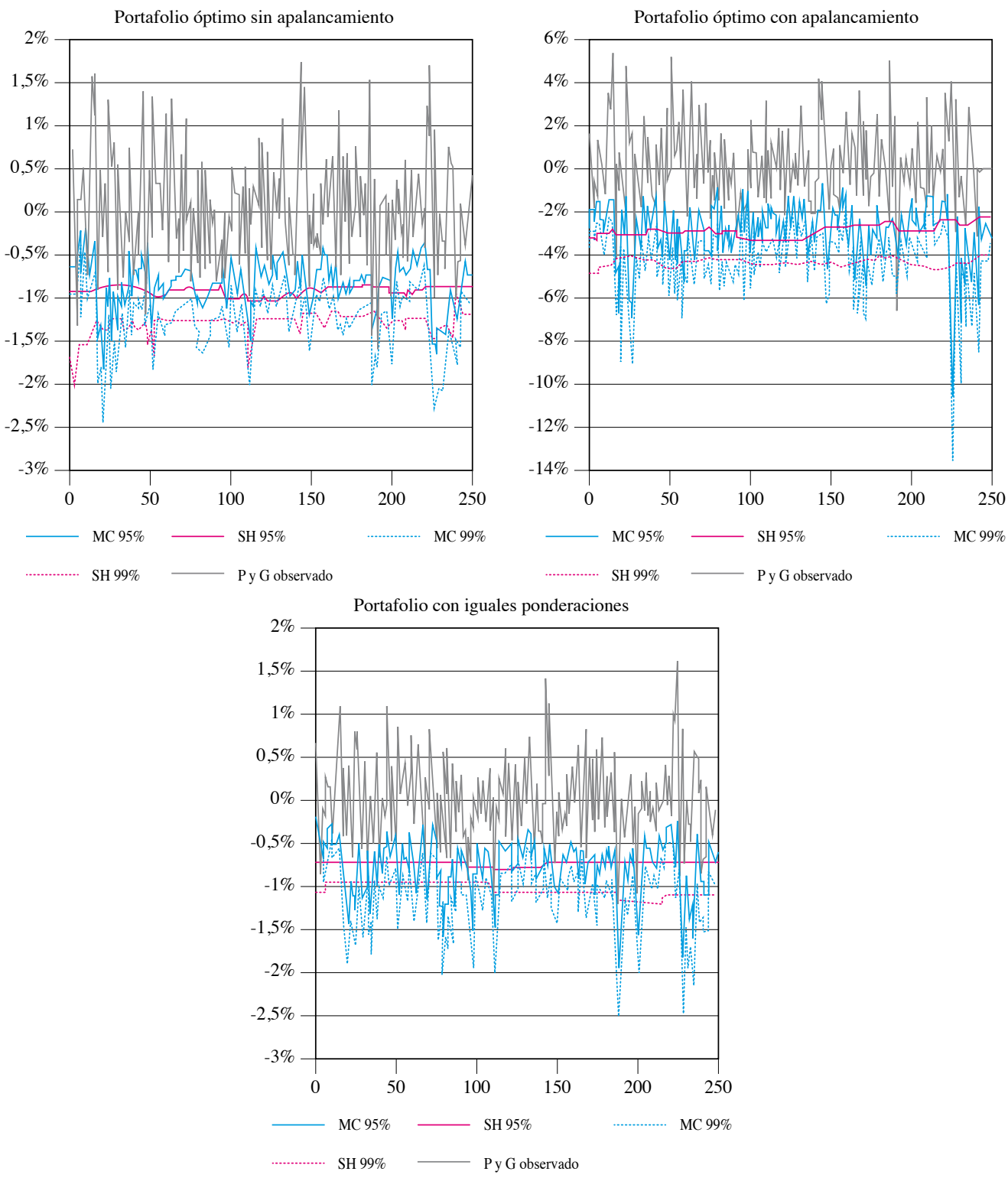

Fuente: elaboración propia. 
Figura 8: Contraste del ES contra PyG observado para la cópula de Clayton
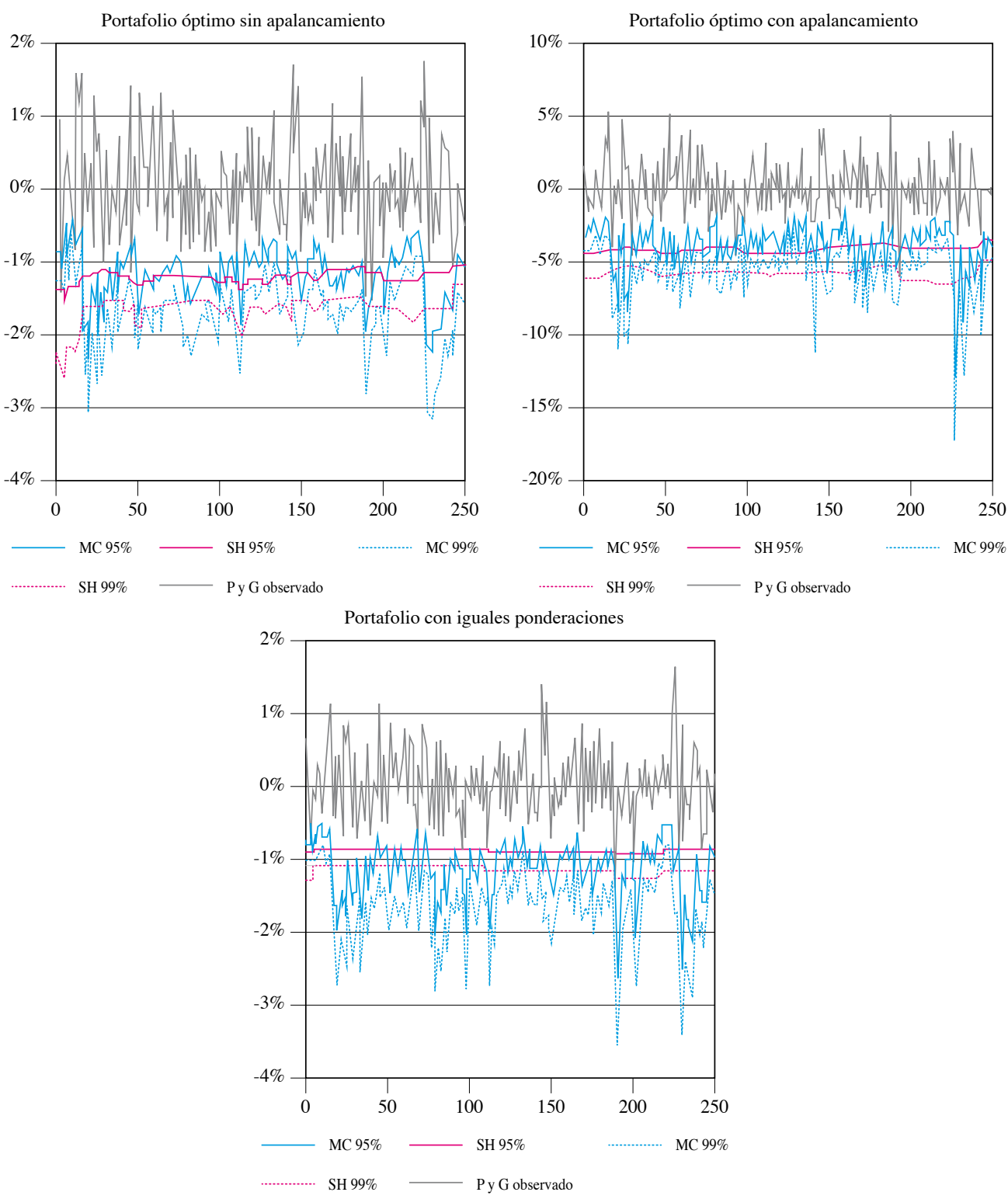

Fuente: elaboración propia. 
Figura 9: Contraste del ES contra PyG observado para la cópula Gaussiana
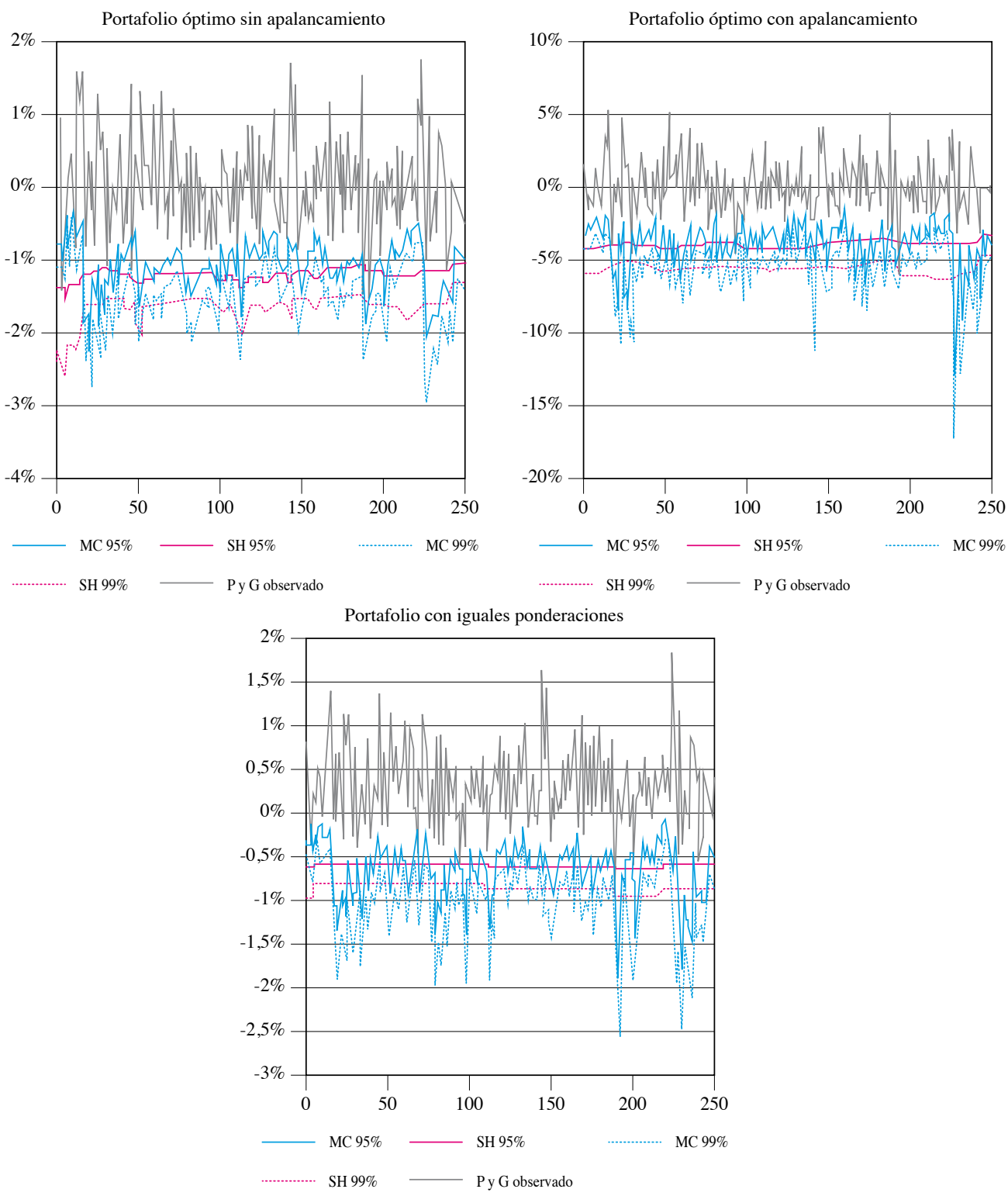

Fuente: elaboración propia. 
Figura 10: Contraste del ES contra PyG observado para la cópula $t$-student
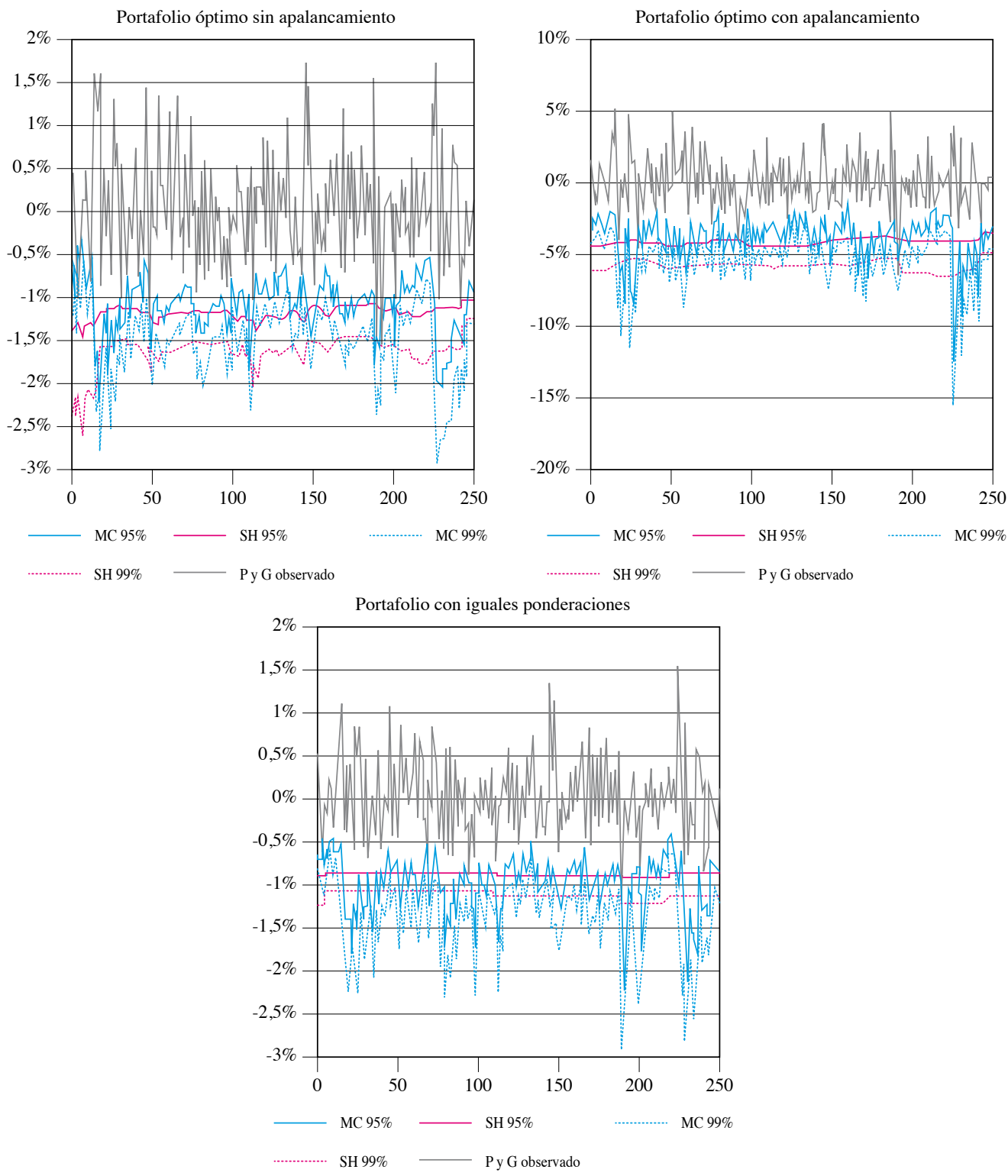

Fuente: elaboración propia. 